\title{
Vaccine targeting SIVmac251 protease cleavage sites protects macaques against vaginal infection
}

\author{
Hongzhao Li, ${ }^{1}$ Robert W. Omange, ${ }^{1}$ Binhua Liang, ${ }^{2,3}$ Nikki Toledo, ${ }^{1}$ Yan Hai, ${ }^{1}$ Lewis R. Liu, ${ }^{1}$ Dane Schalk, ${ }^{4}$ Jose Crecente-Campo, ${ }^{5}$ \\ Tamara C. Dacoba, ${ }^{5}$ Andrew B. Lambe, ${ }^{6}$ So-Yon Lim, ${ }^{7}$ Lin Li, ${ }^{2}$ Mohammad Abul Kashem, ${ }^{1}$ Yanmin Wan, ${ }^{8}$ Jorge F. Correia-Pinto, ${ }^{5}$ \\ Michael S. Seaman, ${ }^{7}$ Xiao Qing Liu, ${ }^{3,9}$ Robert F. Balshaw, ${ }^{10}$ Qingsheng Li, ${ }^{8}$ Nancy Schultz-Darken, ${ }^{4}$ Maria J. Alonso, ${ }^{5}$ \\ Francis A. Plummer, ${ }^{1,2}$ James B. Whitney, ${ }^{7,11}$ and Ma Luo ${ }^{1,2}$ \\ 'Department of Medical Microbiology and Infectious Diseases, University of Manitoba, Winnipeg, Manitoba, Canada. ${ }^{2}$ National Microbiology Laboratory, Public Health Agency of Canada, Winnipeg, \\ Manitoba, Canada. ${ }^{3}$ Department of Biochemistry and Medical Genetics, University of Manitoba, Winnipeg, Manitoba, Canada. ${ }^{4}$ Scientific Protocol Implementation Unit, Wisconsin National Primate Research \\ Center, Madison, Wisconsin, USA. ' Center for Research in Molecular Medicine and Chronic Diseases (CIMUS), Campus Vida, Universidade de Santiago de Compostela, Santiago de Compostela, Spain. \\ ${ }^{6}$ Sightline Innovation, Toronto, Ontario, Canada. ${ }^{7}$ Center for Virology and Vaccine Research, Beth Israel Deaconess Medical Center, Harvard Medical School, Boston, Massachusetts, USA. ${ }^{8}$ Nebraska Center \\ for Virology, School of Biological Sciences, University of Nebraska-Lincoln, Lincoln, Nebraska, USA. ${ }^{9}$ Department of Obstetrics, Cynecology and Reproductive Sciences, University of Manitoba, Winnipeg, \\ Manitoba, Canada. ${ }^{10}$ Centre for Healthcare Innovation, University of Manitoba, Winnipeg, Manitoba, Canada. "'Ragon Institute of MCH, MIT, and Harvard, Cambridge, Massachusetts, USA.
}

\begin{abstract}
After over 3 decades of research, an effective anti-HIV vaccine remains elusive. The recently halted HVTN702 clinical trial not only further stresses the challenge to develop an effective HIV vaccine but also emphasizes that unconventional and novel vaccine strategies are urgently needed. Here, we report that a vaccine focusing the immune response on the sequences surrounding the 12 viral protease cleavage sites (PCSs) provided greater than $80 \%$ protection to Mauritian cynomolgus macaques against repeated intravaginal SIVmac251 challenges. The PCS-specific T cell responses correlated with vaccine efficacy. The PCS vaccine did not induce immune activation or inflammation known to be associated with increased susceptibility to HIV infection. Machine learning analyses revealed that the immune microenvironment generated by the PCS vaccine was predictive of vaccine efficacy. Our study demonstrates, for the first time to our knowledge, that a vaccine which targets only viral maturation, but lacks full-length Env and Gag immunogens, can prevent intravaginal infection in a stringent macaque/SIV challenge model. Targeting HIV maturation thus offers a potentially novel approach to developing an effective HIV vaccine.
\end{abstract}

\section{Introduction}

HIV mutates rapidly and preferentially infects activated CD $4^{+} \mathrm{T}$ cells. Inflammation activates and attracts HIV target cells, thereby enhancing the risk of infection (1-3). These inherent characteristics of HIV infection underscore the unique challenges compared with other pathogens when developing a prophylactic vaccine $(4,5)$. Among the 7 HIV vaccine clinical efficacy trials to date, only the RV144 Thai trial demonstrated efficacy, albeit modest $(31.2 \%)(4,6)$. The recent HVTN702 trial, using a similar subtype C-adapted vaccine, showed no efficacy, and was halted (7). The HVTN702 trial emphasizes that unconventional and novel vaccine strategies should be explored.

Because activated $\mathrm{CD}^{+} \mathrm{T}$ cells are preferential targets for HIV, an effective HIV vaccine would need to elicit protective anti-

Authorship note: $\mathrm{HL}, \mathrm{RWO}$, and $\mathrm{BL}$ contributed equally to this work. FAP is deceased. Conflict of interest: ML is the inventor of patents owned by Her Majesty The Queen In Right of Canada as represented by The Minister of Health: Canada patent no. 2,833,425, "Protease cleavage site peptides as an HIV vaccine"; US patent no. $10,285,942$, "Methods of inducing an immune response against HIV by administering immunogenic peptides obtained from protease cleavage sites"; and European patent no. 2,694,654, "Protease cleavage site peptides as an HIV vaccine." Copyright: () 2020, American Society for Clinical Investigation. Submitted: April 8, 2020; Accepted: August 20, 2020; Published: November 3, 2020. Reference information: / Clin Invest. 2020;130(12):6429-6442. https://doi.org/10.1172/JCl138728.
HIV immunity, while minimizing vaccine-induced inflammation and immune activation $(5,8,9)$. Our studies of HIV highly exposed seronegative (HESN) Kenyan female sex workers demonstrated that narrowly targeted $\mathrm{T}$ cell responses are associated with protection against HIV infection (9-11). Thus, an alternative strategy for an effective HIV vaccine would be to generate and direct the immune responses to only the essential parts of $\operatorname{HIV}(9,12)$. Learning from the natural immunity observed in these Kenyan HESN women, we tested an HIV vaccine strategy by focusing the host immune response on the sequences surrounding the 12 viral protease cleavage sites (PCSs) $(8,13)$. The HIV protease cleaves Gag, Gag-Pol, and Nef precursor proteins at the 12 PCSs $(8,14)$. Studies have shown that the process of protease cleavage requires a tightly controlled and ordered sequence of proteolytic processing events mediated by different rates of cleavage at the different processing sites (15-21). Even subtle disturbances may be sufficient to interrupt this delicately balanced process and drive it toward a nonproductive end $(15,18,19,22)$. We hypothesized that a vaccine targeting the 12 PCSs may be effective against HIV infection. First, as the sequences surrounding the PCSs are highly conserved (8), the vaccine can target multiple HIV-1 subtypes. Second, the focused immunity may drive viral mutations surrounding the PCSs and impair the proteolytic processing of HIV polyproteins. Third, restricting the immune response to a reduced number of 

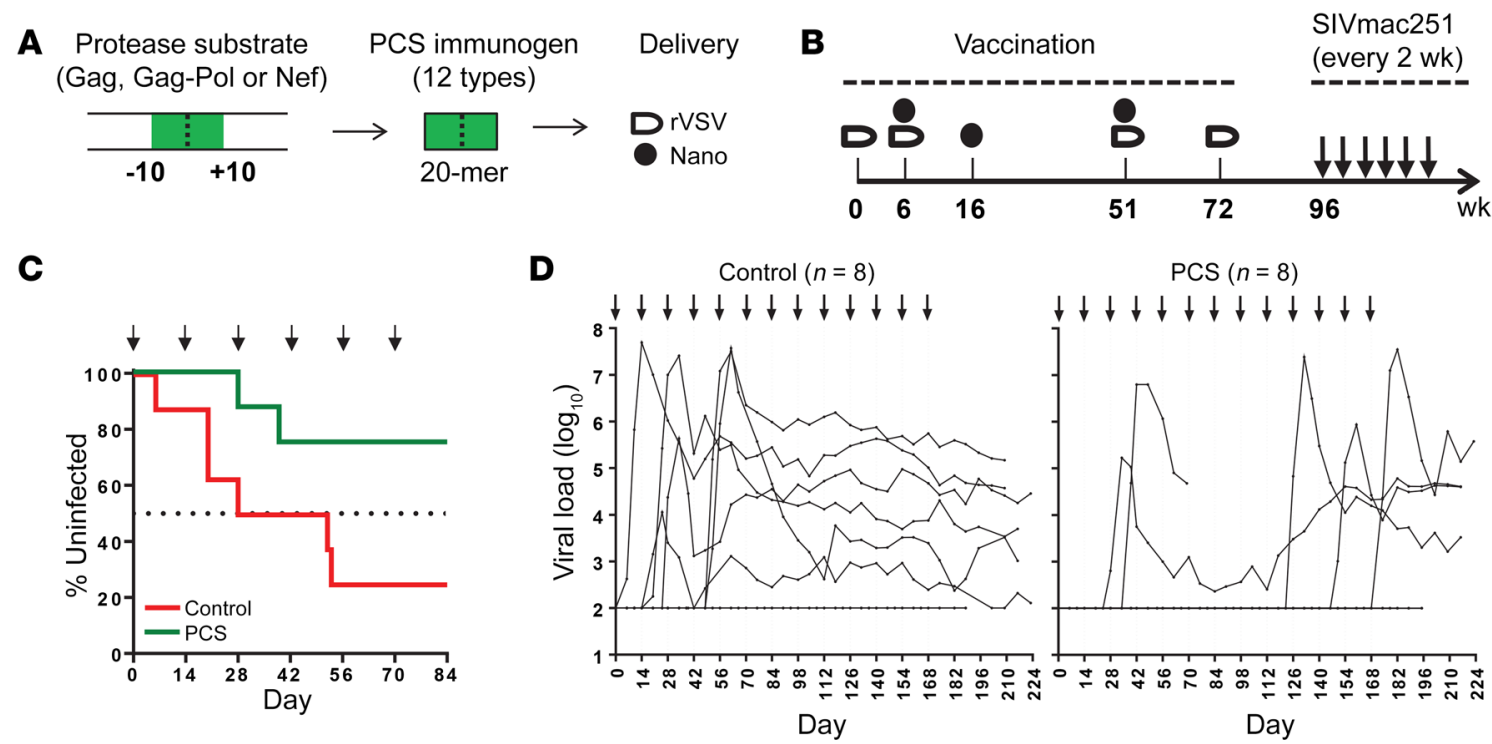

Figure 1. The PCS vaccine protected MCMs against vaginal SIVmac251 infection. (A) The PCS vaccine. Twelve 20-mer peptides derived from the 12 protease cleavage site (PCS) regions of SIVmac239 (between -10 and +10 positions flanking each cleavage site) were delivered as recombinant vesicular stomatitis viruses (rVSV) and nanoparticles (Nano). (B) Immunization and challenge scheme. Two groups of animals were involved, the PCS vaccine group $(n=8)$ and the sham vaccine control group $(n=8)$. (C) Kaplan-Meier plot showing the percentage of uninfected animals following challenges. (D) Extended challenges beyond the predetermined, standard challenge protocol. Viral load time course of each animal (note: $n=8 /$ group, while data of some animals at baseline levels overlap and are not visually distinguishable on graph).

T cell epitopes surrounding the PCSs may result in lower vaccineinduced inflammation and fewer activated $\mathrm{CD} 4^{+} \mathrm{T}$ target cells (8). We tested this hypothesis in a nonhuman primate (NHP)/simian immunodeficiency virus (SIV) infection model. We demonstrate here that the PCS-based vaccine, without full-length Gag or Env immunogens, protects female Mauritian cynomolgus macaques (MCMs) from acquisition of a highly pathogenic and heterogenic SIVmac251 infection (23).

\section{Results}

Vaccine protection against vaginal SIVmac251 infection. The PCS vaccine delivers twelve 20-amino acid peptides overlapping each of the 12 viral PCSs with recombinant vesicular stomatitis viruses (rVSVs) and nanoformulations (NANOs) $(8,13)$. To evaluate the efficacy of the PCS vaccine (Figure 1A), 16 female MCMs that did not express known SIV controller MHC haplotypes (24) (Supplemental Table 1; supplemental material available online with this article; https://doi.org/10.1172/JCI138728DS1) were divided into 2 groups (the PCS vaccine and the vaccine vector control; $n=8$ per group). MHC haplotypes were balanced between the 2 groups (Supplemental Table 2). The vaccination scheme consisted of prime with rVSVpcs or rVSV control vector (intramuscularly) and 4 boosts with combinations of rVSVpcs or rVSV vector (intramuscularly) and NANOpcs (intranasally, Figure 1B) (13).

Approximately 6 months after the final boost, repeated lowdose intravaginal SIVmac251 challenges were carried out every 2 weeks and infection status was monitored by the quantification of plasma viral load (VL) on days 6, 10, and 14 after each challenge (Figure 1B). The vaginal challenge route was chosen to mimic vaginal HIV exposure in women, which accounts for approximately half of all HIV infections worldwide (25). Accord- ing to our study design (see Methods), the end point of the challenge study for evaluating vaccine efficacy was at challenge number 6 (Figure 1C), which has also been used in many other studies $(23,26-28)$. At the end of the challenge protocol, the majority (6 of $8,75 \%$ ) of control animals were infected, whereas only 2 of the PCS-vaccinated animals (25\%) were infected (Figure 1C). To determine whether the 2 (uninfected) control animals were refractory to SIVmac251 infection and to determine the numbers of challenges needed to infect $50 \%$ of the vaccines, we extended to 13 challenges (Supplemental Table 3). Following the extended challenges, 3 additional animals in the PCS vaccine group became infected (after 9, 11, and 13 challenges, respectively). However, the 2 previously uninfected control animals remained uninfected (Supplemental Table 3). This observation was consistent with findings from several previous studies in macaques demonstrating that a portion of control animals were refractory to acquisition of SIV or simian-human immunodeficiency virus (SHIV) infection (28-36).

Survival analysis demonstrated that the PCS vaccine significantly increased the number of challenges required for acquisition of SIVmac251 infection ( $P=0.046$, log-rank test) (Figure $1 \mathrm{C}$ and Table 1). It provided an $80.3 \%$ reduction in the per-exposure risk of viral acquisition (vaccine efficacy $=1$ - hazard ratio, proportional hazards regression) (Figure $1 \mathrm{C}$ and Table 1 ). Moreover, only 2 SIVmac 251 challenges were required to infect $50 \%$ of control animals (Figure 1, C and D, and Table 1). However, 11 successive challenges were needed to infect $50 \%$ of the animals in the PCS vaccine group (Figure 1D and Table 1). This significant level of vaccine protection was not related to the menstrual phases of these female animals during the SIVmac251 challenges (Supplemental Figures 1 and 2) nor their MHC haplotypes (Supplemental Tables 4 and 5). 
Table 1. Statistical analysis of vaccine efficacy

$\begin{array}{lccccc} & \begin{array}{c}\text { Hazard ratio } \\ (95 \% \mathrm{Cl})\end{array} & \text { Per-exposure risk reduction } & \boldsymbol{P} \text { value }^{\mathrm{A}} & \boldsymbol{P}_{\text {value }} & \begin{array}{c}\text { Extended challenge: } \\ \text { challenge number to infect 50\% monkeys }\end{array} \\ \text { Control } & 1 \text { (reference) } & \text { N/A } & \text { N/A } & \text { N/A } & 2 \\ \text { PCS } & 0.197(0.039-0.986) & 80.3 \% & 0.046 & 0.048 & 11\end{array}$

ALog-rank test. ${ }^{B}$ Wald test, proportional hazard model.

These data demonstrate, for the first time to our knowledge, that a candidate prophylactic PCS HIV vaccine, without traditional immunogens, such as full Gag and Env, protected female monkeys against pathogenic SIVmac251 challenges.

The PCS vaccine did not elicit significant inflammatory responses in the cervicovaginal mucosa. Inflammation can activate and attract HIV CD4 ${ }^{+} \mathrm{T}$ target cells to the portal of entry. Elevated cervicovaginal mucosal (CVM) inflammation is associated with increased susceptibility to HIV/SIV infection and reduced efficacy of anti-HIV microbicides (37-39). We examined vaginal mucosal inflammation following vaccination. The vaccine-induced mucosal inflammation was analyzed by quantifying inflammatory cytokine responses in cervicovaginal lavage (CVL) samples (Figure 2, A-G, and Supplemental Figure 3). Thirteen proinflammatory cytokines (TNF- $\alpha$, IFN- $\gamma$, IL-6, RANTES/CCL5, GM-CSF, IL-1 $\beta$, MCP-1/CCL2, IL-8, MIP-1 $\alpha / C C L 3$, MIP-1 $\beta / C C L 4$, IP-10/ CXCL10, IL-17A, and IL-1 $\alpha$ ) and 1 antiinflammatory cytokine (IL-10) were analyzed. Vaccine-induced fold changes in cytokine levels at multiple time points were determined and are shown as heatmaps (Figure 2A). No apparent induction of inflammatory cytokine responses, apart from some sporadic fluctuations, was observed in the control or the PCS vaccine group. The short SIV PCS peptide immunogens in the PCS vaccine did not lead to the persistent increase in cervicovaginal inflammatory responses in the PCS vaccine group in comparison with the control group, except an initial increase after prime in IFN- $\gamma$, IL-6, RANTES, GM-CSF, MCP-1, and IL-17A, which were dampened at later boost points (Figure 2A). A notable exception was that the induction of MCP-1 in the PCS vaccine group was observed after multiple immunizations (Figure 2A).

When the absolute cytokine levels were compared, the PCS vaccine group had significantly lower levels of IFN- $\gamma$ and MIP-1 $\beta$ at week 73 ( 1 week after the final boost), and IL-8 and MIP-1 $\beta$ at week 90 (18 weeks after the final boost), than that of the control group (see Figure 2, B-G). These data indicate that the PCS vaccine did not elicit significant inflammatory responses in the CVM.

The PCS vaccine induced antibody responses. Mucosal antibodies against PCS peptide antigens were measured in CVL and reported previously (13) and plasma samples (Supplemental Figure 4A and Supplemental Figure 5). The patterns of anti-PCS peptide antibody (IgG) responses in CVL and plasma were similar. A trend of increased antibodies against individual PCS antigens was observed at week 73 ( 1 week after the last boost, defined as the "peak" immune response time point) (Supplemental Figure 5). The level of combined plasma antibodies against all 12 PCS peptides at this time point in the PCS vaccine group was approximately 2 -fold higher that in the control group (Supplemental Fig- ure 4A). Thus, the PCS vaccine induced antibodies against PCS peptides. The PCS peptides are not located in the Env, and the prechallenge plasma samples of the PCS vaccine group did not have neutralizing activities against tier 1 and tier 2 SIVmac251 (Supplemental Table 6). The moderate magnitude of anti-PCS antibodies may reflect the existence of B cell epitopes in the sequences surrounding the PCS, and indicate that immunization with the PCS vaccine was effective in inducing antibodies against the PCS peptides. However, the contribution of these antibodies to the protection is currently unknown.

The PCS vaccine induced $T$ cell responses. To examine vaccine-induced cellular immune responses, peripheral blood mononuclear cells (PBMCs) from the peak time point were quantified by ELISPOT for frequency of IFN- $\gamma$-producing cells in response to a pool of SIV peptide antigens (PCS1-4, PCS5-8, or PCS9-12) (Supplemental Figure 4, B-D). Slightly higher numbers of animals in the PCS vaccine group than those in the control group showed above-background responses to PCS5-8 and PCS9-12 peptide pools, but these differences were not statistically significant (Supplemental Figure 4, B-D). Although IFN- $\gamma$ ELISPOT has been traditionally used to evaluate $\mathrm{T}$ cell responses to vaccines, many cytokines other than IFN- $\gamma$ are known to be secreted by activated $\mathrm{T}$ cells (40-42). Thus, simply assessing the IFN- $\gamma$ response by ELISPOT may give a very limited view of vaccine-induced $\mathrm{T}$ cell responses (43). Furthermore, in some vaccine studies, IFN- $\gamma$ secretion was a poor correlate of protection against HIV, and was not the best indicator of vaccine-induced responses (43). We therefore expanded the analysis of cellular responses by measuring 14 cytokines using our customized Bio-Plex multiplexed cytokine assay.

PBMCs of the PCS vaccine group from the peak time point were stimulated with PCS peptide pools and quantified for cytokines secreted into the culture supernatants (Supplemental Table 7). Between 9 and 14 cytokines were detected following stimulations with different PCS peptide pools (PCS1-4: 9 cytokines, PCS5-8 and PCS9-12: 14 cytokines). Among these cytokines, RANTES, MIP- $1 \alpha$, MIP- $1 \beta$, TNF- $\alpha$, IL- 6 , and IL- 8 were detected in $50 \%$ or higher percentages of animals (Supplemental Table 7). Some of these cytokines are currently known to have potential functions in directly inhibiting HIV infection or regulating inflammation. RANTES, MIP- $1 \alpha$, and MIP- $1 \beta$ are HIV-suppressive factors produced by $\mathrm{CD}^{+} \mathrm{T}$ cells possibly through competitive binding of HIV coreceptor CCR5 (44). IL-6, produced by various cell types including T cells, B cells, and monocytes (45), can have an antiinflammatory role in controlling local or systemic acute inflammatory responses $(46,47)$. A source of $\mathrm{IL}-8$ is $\mathrm{CD}^{+}{ }^{+} \mathrm{FOXP}^{+}$ regulatory $\mathrm{T}$ (Treg) cells (48), which could play a role in regulating antiviral responses. In summary, these data indicated that several 
A
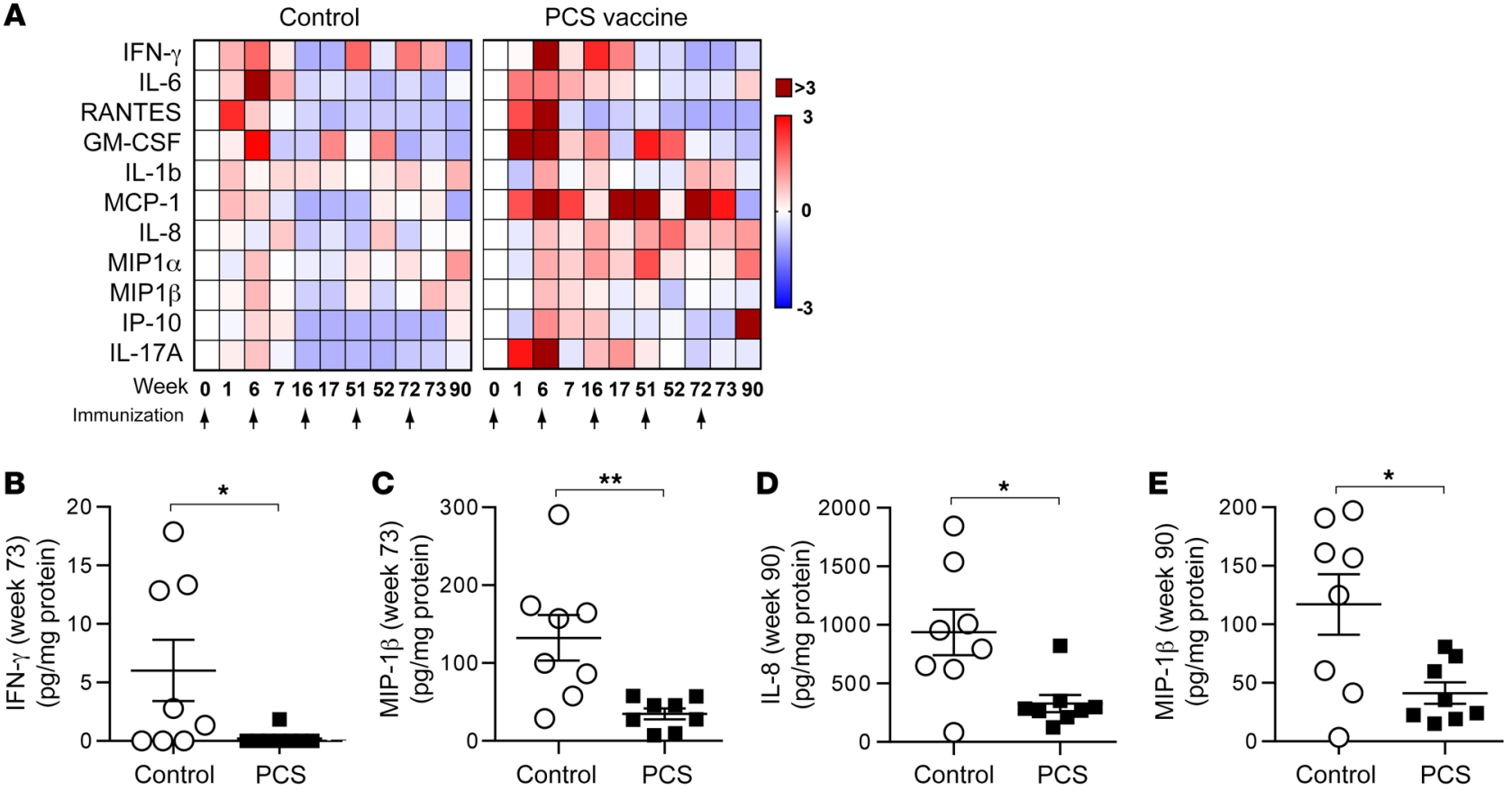

$\mathbf{F}$

Effect of boost 4 (week 72 vs. week 73 )
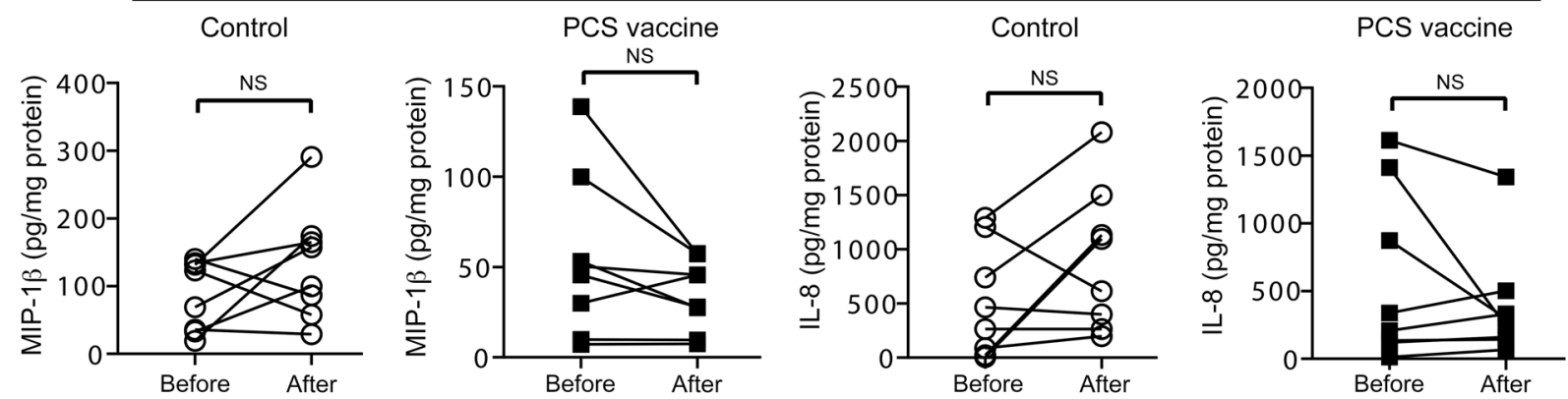

G
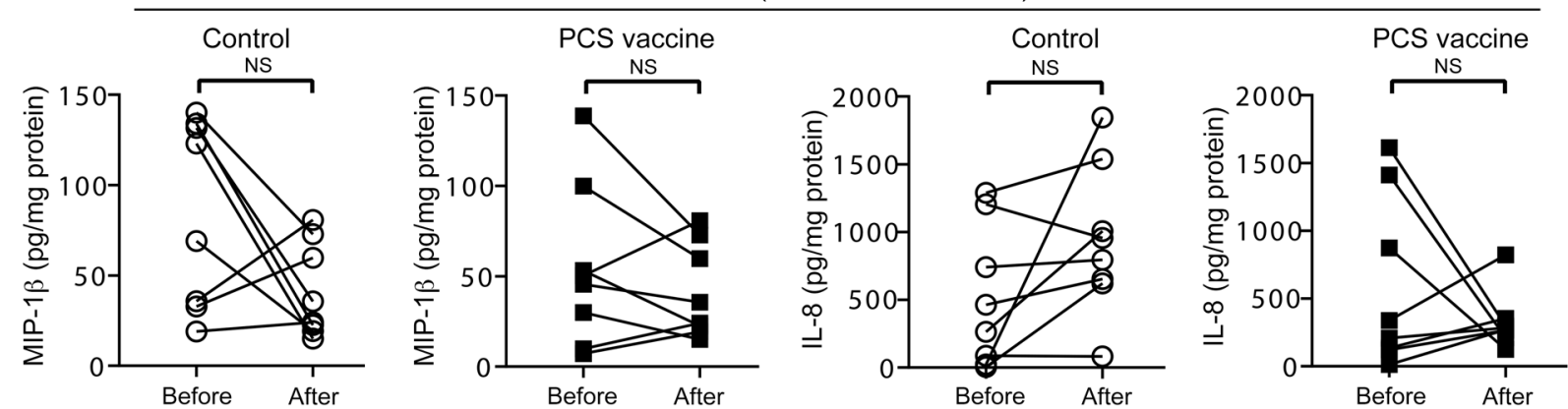

Figure 2. The PCS vaccine and mucosal inflammatory cytokines. (A) Heatmaps showing net fold change (relative to preimmunization baseline) in group median inflammatory cytokine levels at the cervicovaginal mucosa at different time points of the vaccination scheme. A significant increase in MCP-1 after PCS vaccine immunization was observed at weeks 6 and $17(P<0.01)$ as well as week $51(P<0.05)$ by Mann-Whitney $U$ test. (B-E) The PCS vaccine group showed significantly lower levels of several cytokines at indicated time points than the control group. Data are presented as values from individual animals with mean \pm SEM. ${ }^{*} P<0.05,{ }^{* *} P<0.01$ (Mann-Whitney $U$ test). (F) Comparisons of the cytokines in B-E at the fourth boost (week 72 ) and 1 week after (week 73). (G) Comparisons of the cytokines in B-E at the fourth boost (week 72) and 18 weeks after (week 90).

types of cellular immune responses to PCS antigens can be generated following vaccination.

The PCS vaccine generated PCS-peptide-specific CD $8^{+}$T memory and $C D 4^{+}$Treg cells. We characterized the $\mathrm{T}$ cell subsets after immunization. PBMCs from week 90 (prechallenge), without antigen stimulation (ex vivo), or stimulated with a pool of PCS peptides (PCS1-12), were analyzed by flow cytometry (Figures 3 and 4 and Supplemental Figure 6). Different cellular markers (49-51) were chosen to differentiate $\mathrm{CD}^{+}$and $\mathrm{CD} 8^{+} \mathrm{T}$ cell subsets including naive and memory T cells (CCR7 and CD45RA) (52, 
A

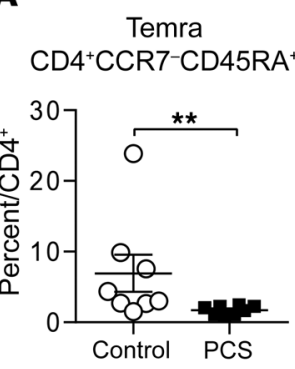

F Th17 naive $\mathrm{CD}^{+}$IL-17A ${ }^{+} \mathrm{CCR} 7^{+}$ $\mathrm{CD}^{4} 5 \mathrm{RA}^{+} \mathrm{CCR}^{+} \mathrm{MFI}$

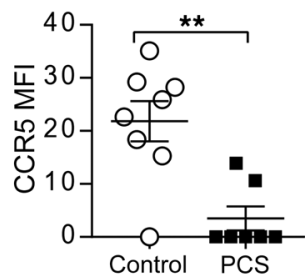

B Temra $\mathrm{CD}^{+}{ }^{+} \mathrm{CCR} 7-\mathrm{CD} 45 \mathrm{RA}^{+}$ $\mathrm{Ki} 67^{+} \mathrm{MFI}$

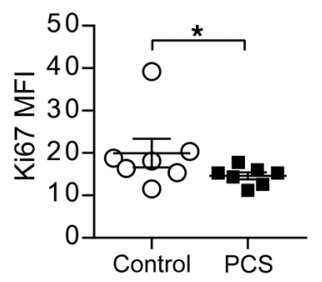

C $\mathrm{CD}^{+}{ }^{+} \mathrm{CCR} 7-\mathrm{CD} 45 \mathrm{RA}^{+}$ TNF- $\alpha^{+}$

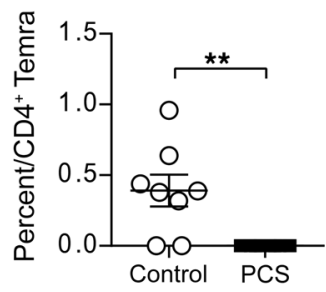

D $\mathrm{CD}^{+}{ }^{+} \mathrm{CCR} 7-\mathrm{CD} 45 \mathrm{RA}^{+}$ TNF- $\alpha^{+}$MFI

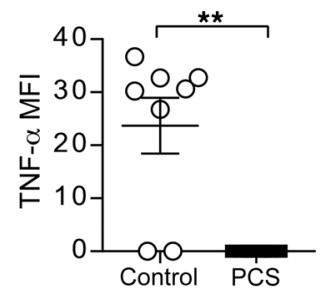

E Tem CD4 ${ }^{+} \mathrm{CCR} 7-\mathrm{CD} 45 \mathrm{RA}^{+}$ TNF- $\alpha^{+}$MFI

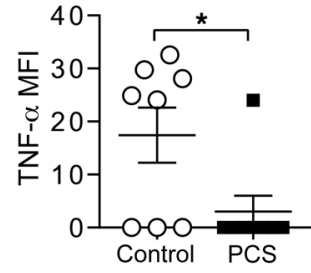

$\mathrm{CD}^{+} \mathrm{IL}^{-17 \mathrm{~A}^{+}} \mathrm{T}$ naive
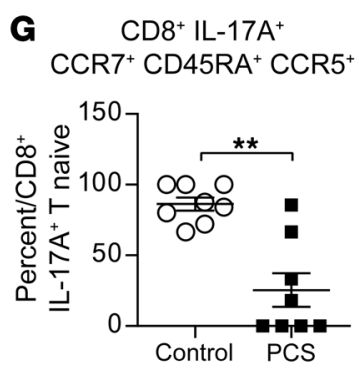

H $\mathrm{CD}^{+} \mathrm{IL}-17 \mathrm{~A}^{+} \mathrm{CCR} 7^{+}$ CD45RA ${ }^{+} \mathrm{CCR}^{+} \mathrm{MFI}$

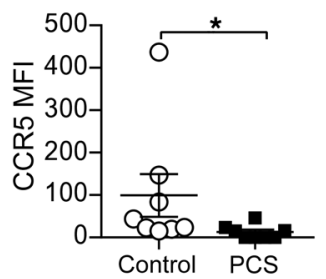

I $\mathrm{CD}^{+} \mathrm{IL}-17 \mathrm{~A}^{+} \mathrm{CCR} 7^{+}$ $\mathrm{CD}_{45 \mathrm{RA}}{ }^{+} \mathrm{CD} 38^{+} \mathrm{MFI}$

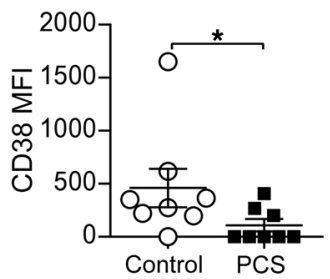

J CD8 ${ }^{+} \mathrm{IL}-17 \mathrm{~A}^{+} \mathrm{CCR} 7^{+}$ $\mathrm{CD}^{2} 5 \mathrm{RA}^{+} \mathrm{CD}^{+} 9^{+} \mathrm{MF}$

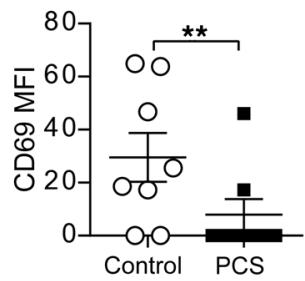

Figure 3. The PCS vaccine induced CD4+ and CD8+ $\mathbf{T}$ cell responses (ex vivo). (A-J) PBMCs from the prechallenge time point (week 90 ) without antigen stimulation were analyzed by multicolor flow cytometry. Definition of T cell subsets based on cellular markers. Tcm, central memory T cells; Tem, effector memory T cells; Temra, CD45RA+ effector memory T cells. Gating strategy is shown in Supplemental Figure 6, A-J: comparisons of cellular subsets between the control and PCS vaccine group. Data are presented as values from individual animals $(n=8)$ with median lines. Statistical significance of differences was determined by Mann-Whitney $U$ test. ${ }^{*} P<0.05,{ }^{*} P<0.01$.

53), Th17 cells (IL-17A and CCR5) (4, 54), and Treg cells (CD25, FOXP3, and CD127) (54), together with activation and differentiation markers including CD38, CD69, CD107a, Ki-67, PD-1, IL-2, TNF- $\alpha$, IFN- $\gamma$, MIP-1 $\beta$, and IL-10.

With PCS peptide stimulation the PCS vaccine group had a significantly higher frequency of $\mathrm{CD} 8^{+}$central memory T cells (CD8 ${ }^{+}$ Tcm: $\mathrm{CD}^{+} \mathrm{CCR}^{+} \mathrm{CD}^{2} 4 \mathrm{RA}{ }^{-}$) (Figure $4 \mathrm{E}$ ). Higher proportions of these $\mathrm{CD}^{+}{ }^{+} \mathrm{Tcm}$ cells expressed CD107a (Figure 4F), an indication of better potential in killing virus-infected cells. Thus, PCS vaccine immunization generated PCS-peptide-specific $\mathrm{CD} 8^{+} \mathrm{Tcm}$ cells that have better antiviral potential. However, the PCS-vaccinated monkeys had fewer CD8 ${ }^{+} \mathrm{Tcm}$ cells expressing IFN- $\gamma$ (Figure 4G).

Antigen-specific Treg cells protect against aberrant immune responses (51). The frequency of PCS-peptide-specific effector memory CD45RA ${ }^{+}$Treg cells (Treg EMRA: $\mathrm{CD} 4^{+} \mathrm{CD} 25^{+} \mathrm{FOXP} 3^{+}$ $\left.\mathrm{CD}^{2} \mathrm{RA}^{+} \mathrm{CD}^{2} \mathrm{R}^{-}\right)$in the PCS vaccine group was higher, and a higher proportion of PCS-peptide-specific naive Treg cells $\left(\mathrm{CD} 4{ }^{+} \mathrm{CD} 25^{+} \mathrm{FOXP}^{+} \mathrm{CD} 45 \mathrm{RA}^{+} \mathrm{CD} 127^{+}\right)$expressed immunoregulatory cytokine IL-10 compared with that of the control group (Figure 4 , J and $\mathrm{K}$ ). Thus, the PCS vaccine group may have a balanced antiviral immune response and immune activation.

The PCS vaccine generated reduced immune activation. The PCS vaccine group had a lower frequency of viral target cells. These included a lower frequency of $\mathrm{CD}^{+}$terminal effector $\mathrm{T}$ cells (CD4 ${ }^{+}$Temra: CD4 ${ }^{+}$CCR7 ${ }^{-}$CD $45 \mathrm{RA}^{+}$) (Figure $3 \mathrm{~A}$ ) and lower CCR5 expression of Th17 naive cells (Figure 3F) under ex vivo conditions. With PCS peptide stimulation the PCS vaccine group had fewer $\mathrm{CD}^{+}$effector memory $\mathrm{T}$ cells (CD4 $\left.{ }^{+} \mathrm{Tem}: \mathrm{CD}^{+}{ }^{+} \mathrm{CCR} 7^{-} \mathrm{CD} 45 \mathrm{RA}-{ }^{-}\right)$ (Figure 4A), and their $\mathrm{CD} 4^{+}$naive $\mathrm{T}$ cells and Th17emra cells had lower CD107a expression (Figure 4, D and H). Furthermore, in the
PCS vaccine group these viral target cells were less activated, as fewer of the $\mathrm{CD} 4^{+}$Temra cells expressed TNF- $\alpha$ (Figure 3C), and the amounts of proliferation marker Ki-67 and proinflammatory cytokine TNF- $\alpha$ expressed by these cells were also significantly lower (Figure 3, B and D).

The overall immune activation status of the PCS vaccine group is also shown by their $\mathrm{CD} 8^{+} \mathrm{T}$ cells. Under ex vivo conditions the PCS vaccine group had a lower frequency of CD $8^{+}$Th17 naive cells (Figure 3G) and lower CCR5, CD38, and CD69 expression on these cells (Figures 3, H-J). Their $\mathrm{CD}^{+}$terminal effector $\mathrm{T}$ cells $\left(\mathrm{CD} 8^{+}\right.$Temra: $\left.\mathrm{CD} 8^{+} \mathrm{CCR}^{-} \mathrm{CD} 45 \mathrm{RA}^{+}\right)$also expressed lower levels of TNF- $\alpha$ (Figures 3E). With PCS peptide stimulations the frequencies of CD8 $8^{+} \mathrm{Th} 17 \mathrm{~cm}$ cells of the PCS vaccine group was significantly lower than that of the controls (Figure 4I). CD $8^{+}$Th17 cells are considered to be important in inflammatory disease (5557). Thus, immunization with the PCS vaccine generated fewer virus-susceptible target cells and lower immune activation.

Of note, although the frequencies of viral target cells were lower in the PCS vaccine group, the CD45RA expression on $\mathrm{CD} 4^{+}$Temra cells and CCR7 expression on $\mathrm{CD} 4^{+} \mathrm{Tcm}$ cells $\left(\mathrm{CD} 4^{+}\right.$ $\mathrm{CCR}^{+} \mathrm{CD} 45 \mathrm{RA}^{-}$) were significantly higher in the PCS vaccine group (Figure 4, B and C).

Immunologic correlates of vaccine protection. We conducted statistical analysis to identify potential immunologic factors that might be correlated with protection against acquisition of SIVmac251 infection in the PCS-vaccinated group. We assessed immunological measurements, including CVL mucosal inflammatory cytokines, CVL and plasma antibodies, PBMC cytokine-producing antigen recall responses, and $\mathrm{CD} 4^{+}$or $\mathrm{CD} 8^{+} \mathrm{T}$ cell subsets (memory, $\mathrm{IL}-17 \mathrm{~A}^{+}$ and Treg, ex vivo or Ag recall) from the peak (week 73) and prechal- 
A

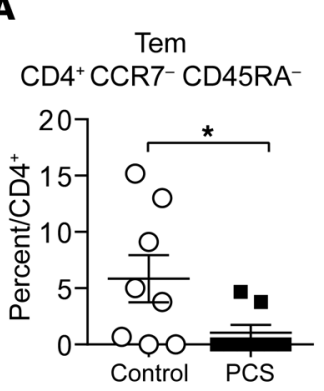

E $\mathrm{Tcm}$
$\mathrm{CD} 8$

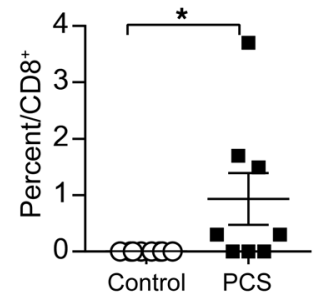

I Th17 Tcm $\mathrm{CD}^{+} \mathrm{IL}-17 \mathrm{~A}^{+}$ $\mathrm{CCR}^{+}{ }^{\mathrm{CD}} 45 \mathrm{RA}^{-}$CD107a ${ }^{+}$

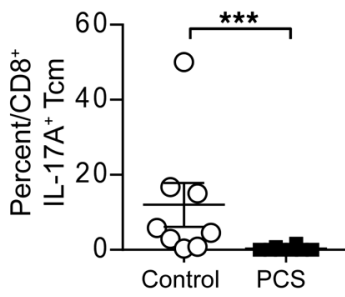

B
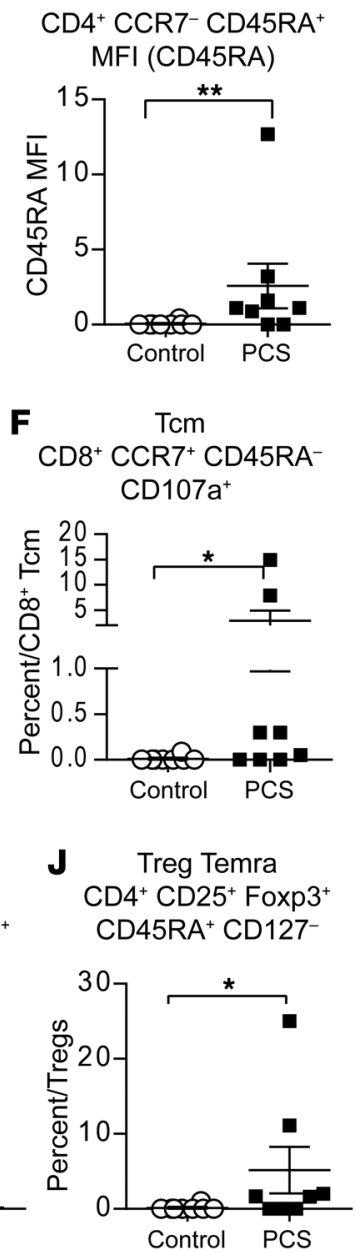

C $\mathrm{CD} 44^{+} \mathrm{CCR} 7^{+} \mathrm{CD} 45 \mathrm{RA}$
$\mathrm{MFI}(\mathrm{CCR} 7)$
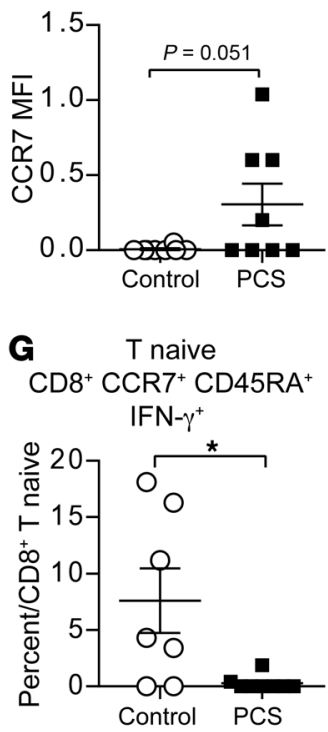
K Treg naive $\mathrm{CD}^{+} \mathrm{CD} 25^{+} \mathrm{Foxp}^{+}$ $\mathrm{CD}^{2} 5 \mathrm{RA}^{+} \mathrm{CD} 127^{+} \mathrm{IL}-10^{+}$

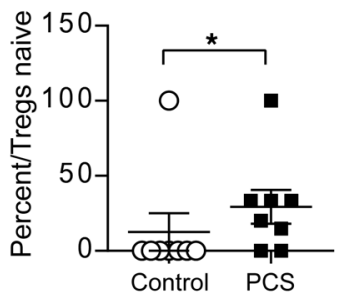

Figure 4. The PCS vaccine induced CD4+ and $\mathbf{C D 8}^{+} \mathbf{T}$ cell responses (recall). (A-K) PBMCs from the prechallenge time point (week 90 ) stimulated with antigen (total PCS peptide pool: PCS1-12) were analyzed by multicolor flow cytometry. Definition of T cell subsets based on cellular markers. Tcm, central memory T cells; Tem, effector memory T cells; Temra, CD45RA+ effector memory T cells. Gating strategy is shown in Supplemental Figure 6, A-K: comparisons of cellular subsets between the control and PCS vaccine group. Data are presented as values from individual animals $(n=8)$ with median lines. Statistical significance of differences was determined by Mann-Whitney $U$ test. ${ }^{*} P<0.05,{ }^{* *} P<0.01,{ }^{* *} P<0.001$.

lenge (week 90) time points. The Spearman rank correlation was first used to assess individual immunological correlates of protection (CoPs) observed in the PCS vaccine group, defined as the number of challenges required for SIVmac251 infection. The identified CoPs (Table 2) (positive Spearman's $\rho$ with $P<0.05$, unadjusted for multiple inference) include (i) cytokines secreted by PBMCs (peak time point) after PCS peptide stimulations, comprising RANTES and IL-6 (to PCS1-4 peptides) and MIP-1 $\alpha$ (to PCS9-12 peptides); (ii) the frequency of CCR5-expressing Th17 Tem (CD4+IL-17A ${ }^{+}$ $\mathrm{CCR7}^{-} \mathrm{CD} 45 \mathrm{RA}^{-}$) cells (prechallenge time point, ex vivo); (iii) the frequency and intensity of CCR5-expressing CD8 $\mathrm{IL}^{+} 17 \mathrm{~A}^{+} \mathrm{Tem}$ cells $\left(\mathrm{CD}^{+} \mathrm{IL}-17 \mathrm{~A}^{+} \mathrm{CCR} 7^{+} \mathrm{CD} 45 \mathrm{RA}^{-}\right)$(prechallenge time point, ex vivo); and (iv) the frequency of the PCS-peptide-specific Treg effector memory cell population $\left(\mathrm{PD}-1^{+} \mathrm{CD} 4^{+} \mathrm{CD} 25^{+} \mathrm{FOXP} 3^{+}\right.$ $\left.\mathrm{CD}^{2} \mathrm{RA}^{+} \mathrm{CD} 127^{-}\right)$(prechallenge). These results suggested that protection was significantly correlated with $\mathrm{T}$ cell responses. However, no significant associations with antibody response were observed.

Several immune correlates of risk (CoRs) (defined as negative Spearman's $\rho$, with $P<0.05$, unadjusted for multiple compari- sons) were also identified, including CVL mucosal IL-1 $\alpha$ level at the peak and prechallenge time points, CVL mucosal antibodies against PCS1, $-3,-4,-5$, and -9 at the peak time point, as well as the frequency or intensity of several activation or differentiation makers on subsets of $\mathrm{CD}^{+}$or $\mathrm{CD}^{+}$memory, $\mathrm{IL}^{-} 17 \mathrm{~A}^{+}$, or Treg cells at the prechallenge time point (Supplemental Table 8). These CoRs appear to relate to inflammation, immune activation, and SIV target cell availability.

To explore more potential CoP/CoRs, especially combinations of immunological predictors that might act together to protect the vaccinated animals, we performed a multiple regression analysis of the immunological data using the LASSO (least absolute shrinkage and selection operator) (Figure 5). Although the risk of overfitting is large, and $R^{2}$ optimistic $\left(R^{2}=0.964\right)$ in this situation, the LASSO regression model nevertheless identified 6 potential predictors, all from prechallenge $\mathrm{T}$ cell subsets, 5 of which were not identified via the single predictor Spearman's correlation analysis (Figure 5A, Table 3, and Supplemental Table 9). Individually, these predictors also positively correlated with many other immunolog- 
Table 2. Immune correlates of protection (CoPs)

Immune response

\begin{tabular}{|c|c|c|c|c|c|}
\hline Type & Subtype & Antigen & Time point & $\rho$ & $P$ \\
\hline Cytokine secretion (Ag recall) & RANTES & PCS1-4 peptide pool & Peak & 0.8500 & 0.0075 \\
\hline Cytokine secretion (Ag recall) & MIP-1 $1 \alpha$ & PCS9-12 peptide pool & Peak & 0.7798 & 0.0225 \\
\hline Cytokine secretion (Ag recall) & IL-6 & PCS1-4 peptide pool & Peak & 0.7148 & 0.0463 \\
\hline CD8+IL-17+ T cells (ex vivo) & $\mathrm{CCR5}^{+} \%$ of $\mathrm{CD}^{+} \mathrm{IL}-17^{+} \mathrm{CCR} 7^{+} \mathrm{CD} 45 \mathrm{RA}^{-}$ & $\mathrm{N} / \mathrm{A}$ & Prechallenge & 0.8539 & 0.0070 \\
\hline CD8+IL-17+ T cells (ex vivo) & CCR5 MFI of CD8+IL-17+CCR7+CD45RA- & $\mathrm{N} / \mathrm{A}$ & Prechallenge & 0.7563 & 0.0299 \\
\hline $\mathrm{CD}^{+}{ }^{+} \mathrm{CD} 25^{+} \mathrm{FOXP3}{ }^{+} \mathrm{T}$ cells (Ag recall) & $\mathrm{PD}-1^{+} \%$ of $\mathrm{CD} 4^{+} \mathrm{CD}^{2} 5^{+} \mathrm{FOXP3} 3^{+} \mathrm{CD} 45 \mathrm{RA}^{+} \mathrm{CD} 127^{-}$ & PCS1-12 peptide pool & Prechallenge & 0.8660 & 0.0054 \\
\hline
\end{tabular}

Immune factors significantly correlating with number of challenges needed to cause infection were determined by Spearman's rank correlation analysis $\mathrm{Ag}$, antigen (used to quantify antibody or to stimulate cells); CVL: cervicovaginal lavage; N/A, not applicable; Ab, antibody; MFI, mean fluorescence intensity. Peak time point: week 73 of vaccination schedule (1 week after final vaccination boost). Prechallenge time point: week 90 of vaccination schedule. Ex vivo: peripheral blood mononuclear cells (PBMCs) were not stimulated with Ag. Ag recall: PBMCs were stimulated with Ag in culture. All analyses were conducted in the PCS vaccine group $(n=8)$.

ical variants by Spearman's rank correlation analysis (Figure 5B and Supplemental Table 9).

The 3 predictors with positive coefficients in the LASSO model were correlated with several cytokine-producing antigen recall responses at the peak or prechallenge time point. They were also positively correlated with the frequency or expression intensity of CD107a, TNF- $\alpha$, MIP-1 $\beta$, CD38, IFN- $\gamma$, IL-2, or CD69 in several $\mathrm{T}$ cell subsets $\left(\mathrm{Th} 17 \mathrm{em}, \mathrm{Th} 17 \mathrm{~cm}, \mathrm{CD} 8^{+} \mathrm{IL}-17 \mathrm{~A}^{+} \mathrm{Tcm} / \mathrm{em}, \mathrm{CD} 8^{+}\right.$ T naive/em, $\mathrm{CD}^{+}{ }^{+} \mathrm{Temra}, \mathrm{CD} 4^{+} / \mathrm{CD}^{+}$Treg naive or $\mathrm{CD} 4^{+}$Treg resting memory) either under ex vivo conditions or after PCS peptide stimulations at the prechallenge time point (Figure $5 \mathrm{~B}$ and Supplemental Figures 7-9). The predictor CD4TregEmPD1, the frequency of PCS-peptide-specific Treg effector memory cells, was strongly correlated with 14 variants. Seven of the 14 variants plus the predictor itself also individually significantly correlated with vaccine protection.

The 3 predictors with negative coefficients in the LASSO model positively correlated with the fold change of 2 CVL mucosal cytokines, RANTES and IL-17A, at the prechallenge time point, and with CVL antibodies against PCS4 and PCS5 at the peak time point (Figure 5B and Supplemental Figures 10-12). The predictor CD4TreNPD1m, the PD-1 expression on naive Treg cells, appeared to play an important role in regulating proliferation of several $\mathrm{T}$ cell subsets, as shown by its significant correlation with Ki-67 frequency or/and expression intensity in $\mathrm{CD}^{+}$and $\mathrm{CD} 8^{+}$ $\mathrm{T}$ naive, Tem, Tcm, and Temra cells under ex vivo conditions or after PCS peptide stimulations. CD4TreNPD1m also correlated with the frequency or/and expression intensity of CD38, IFN- $\gamma$, and PD- 1 in CD8 ${ }^{+} \mathrm{IL}_{-17 \mathrm{~A}^{+}} \mathrm{T}$ naive, $\mathrm{CD} 8^{+}$Temra, and $\mathrm{CD} 4^{+}$Treg effector memory under ex vivo conditions and/or after PCS peptide stimulations (Supplemental Table 9). The other 2 predictors with negative coefficients in the LASSO model, CD8TregCmIL10 and $\mathrm{CD} 4 \mathrm{TreCmCD} 38$, significantly correlated with the frequencies of CCR5 $5^{+}$Th17 naive cells after PCS peptide stimulation. The frequencies of these 2 central memory Treg cells significantly correlated with the frequency or expression intensity of IL-10, CD38, CD69, MIP-1 $\beta$, and PD- 1 in CD $4^{+}$Treg naive, CD4 ${ }^{+}$Treg effector memory, $\mathrm{CD}^{+}$Treg naive, $\mathrm{CD} 8^{+}$Treg $\mathrm{RM}, \mathrm{CD}^{+}$Treg effector memory, or $\mathrm{CD}^{+}$Treg central memory cells under ex vivo conditions or after PCS peptide stimulations (Supplemental Table 9). These 2 predictors also correlated with the expression intensity of CD107a in CD8 ${ }^{+} \mathrm{IL}_{-}-17 \mathrm{~A}^{+} \mathrm{T}$ naive, CD8 ${ }^{+} \mathrm{IL}-17 \mathrm{~A}^{+} \mathrm{Tem}$, and Th17 Temra cells, as well as the expression intensity of CD38 and IFN- $\gamma$ in Th17emra cells (Supplemental Table 9).

Of the 6 predictors identified by the LASSO model, 4 are PCS-peptide-stimulated Treg cells. These antigen-specific Treg cells appear to act together with PCS-peptide-specific IL-2 ${ }^{+} \mathrm{CD} 8^{+}$ Tcm cells and PCS-peptide-specific CD107a $\mathrm{IL}^{-17^{+} \mathrm{CD} 8^{+} \mathrm{Tem}}$ cells to regulate the immunological microenvironment in the vaccinated macaques and contribute to the effective protection against pathogenic SIVmac251 acquisition.

\section{Discussion}

The development of an effective HIV vaccine is faced with significant challenges. HIV has the formidable capacity to mutate its genome and evolves rapidly to evade immune recognition (5860). It targets $\mathrm{CD}^{+} \mathrm{T}$ cells and thrives in an activated immune environment, distinguishing it from other infectious pathogens $(4,5)$. The knowledge gained from prior HIV vaccine development (61) and from the natural immunity of highly exposed seronegative individuals (9) are important in developing an effective HIV vaccine. Traditional candidate vaccines have been based on fulllength HIV proteins such as Env and Gag, which contain multiple immunodominant decoy epitopes that may divert immune responses away from targeting protective epitopes or enhanced activation of $\mathrm{CD}^{+} \mathrm{T}$ cells $(62,63)$. It has been proposed that the increased risk of infection observed in the vaccinees of the STEP (HVTN 502) and Phambili (HVTN 503) trials may have resulted from increased activation of mucosal $\mathrm{CD} 4^{+} \mathrm{T}$ cells following vaccination $(6,64,65)$. This hypothesis is supported by preclinical data of similar vaccine studies in NHPs $(6,64,65)$. In the RV144 trial, the ALVAC vaccine used for prime was found to have much lower immunogenicity than the highly immunogenic Ad5 vaccine in the STEP trial $(66,67)$. An NHP study mimicking the RV144 trial and its follow-up African trial observed that replacing the vaccine adjuvant alum with more immunostimulatory MF59 resulted in 
A

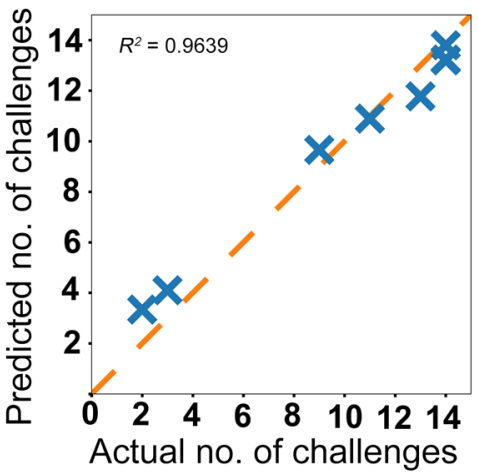

Figure 5. Immune predictors identified by LASSO analysis predict vaccine efficacy. (A) LASSO model: Plot of actual versus predicted numbers of challenges from the identified immune predictors. (B) Networks of the identified immune predictors with other immune variants positively correlated the identified predictors by Spearman's rank analysis (Supplemental Table 9). The 6 identified predictors (Table 3) are labeled as big circled nodes in different colors. Green: predictors with positive coefficient; blue: predictors with negative coefficient. Close-up view of the networks is available in Supplemental Figures 7-12.

B
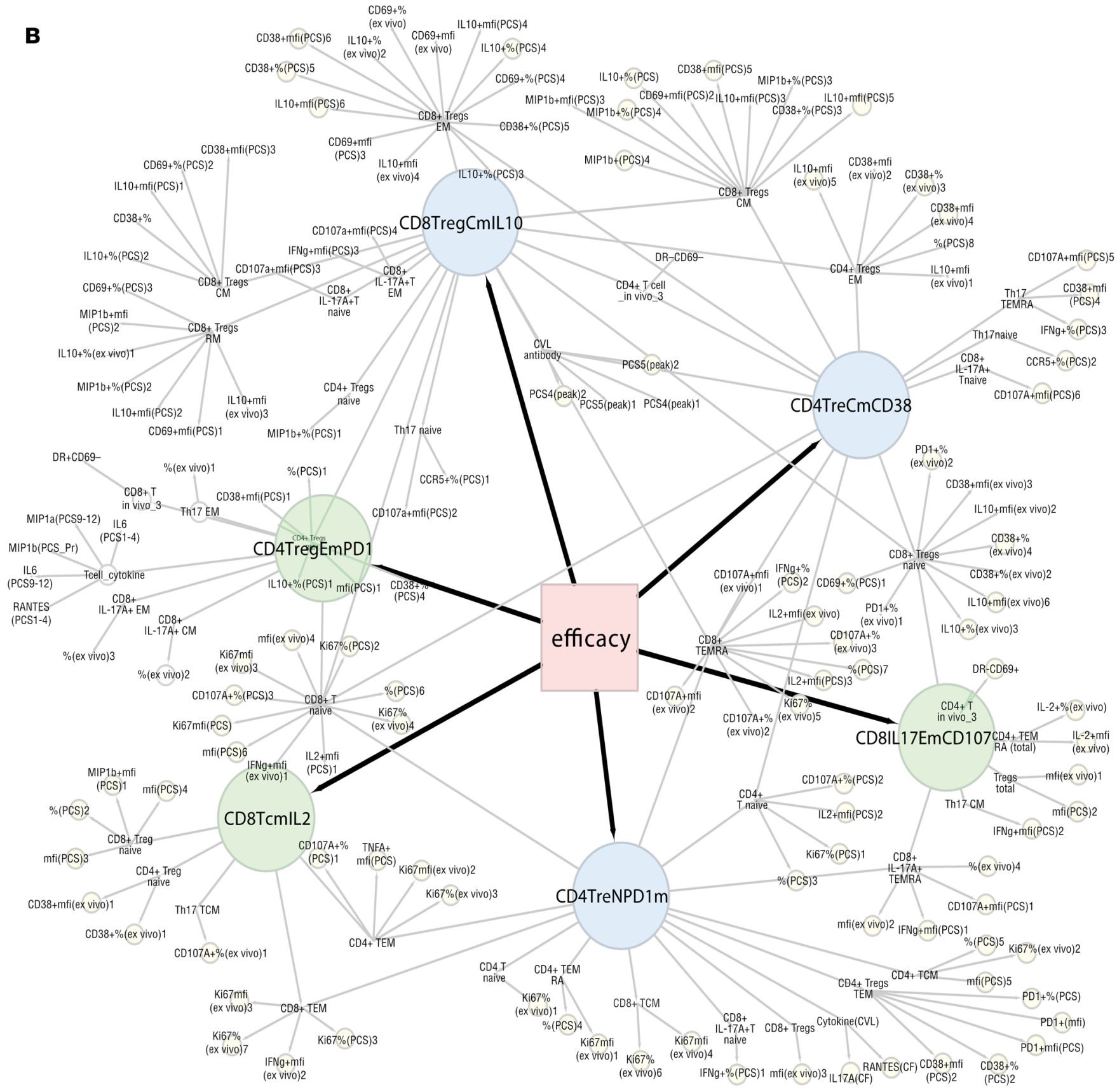
Table 3. The identified predictors and their coefficients of LASSO model

\begin{tabular}{|c|c|c|c|}
\hline Predictor no. & Predictor name & Immune variants & Coefficients \\
\hline P1 & CD4TregEmPD1 & CD4 ${ }^{+}$Treg EM PD $-1^{+} \%$ & 2.1849 \\
\hline $\mathrm{P} 2$ & CD8IL17EmCD107 & CD8+IL-17A Tem CD107a $\%$ & 0.7559 \\
\hline P3 & CD8TcmlL2 & $\mathrm{CD}^{+} \mathrm{Tcm} \mathrm{IL}-2^{+} \%$ & 0.1289 \\
\hline P4 & CD4TreNPD1m & $\mathrm{CD}^{+}$Treg Naive PD1+ MFI & -1.2588 \\
\hline P5 & CD8TregCmIL10 & CD8 ${ }^{+}$Treg CM IL-10+\% & -3.6970 \\
\hline P6 & CD4TreCmCD38 & $\mathrm{CD}^{+}$Treg CM CD38% & -5.3712 \\
\hline \multicolumn{4}{|c|}{$\begin{array}{l}y=10.8932+(2.1849 \times P 1)+(0.7559 \times P 2)+(0.1289 \times P 3)-(1.2588 \times P 4)-(3.6970 \times \\
P 5)-(5.3712 \times P 6) .\end{array}$} \\
\hline
\end{tabular}

loss of the protective effect (68). Such data need to be considered in development and evaluation of future HIV vaccines. Our data indicate that the PCS vaccine may obviate some of these concerns and can provide more than $80 \%$ protection to macaques against repeated intravaginal SIVmac251 challenge.

MCMs are susceptible to SIV and SHIV infection and have a natural course of SIV/SHIV infection leading to simian AIDS that recapitulates HIV infection in humans. Thus, they are considered a valid vaccine model $(24,69-82)$. They are comparable to rhesus macaques in terms of viral infectivity and peak VL level based on inoculation through oral and rectal mucosal routes (83). Furthermore, SIVmac251 is highly pathogenic, with significant genetic heterogeneity (82). Moreover, the repetitive low-dose SIVmac251 intravaginal challenges used in our studies employed virus titers far exceeding the average HIV VL in human semen (84-86).

The overall efficacy of the PCS vaccine is among those of the best protective vaccines thus far tested in NHP/pathogenic SIVmac251 models $(23,27,87)$. The PCS vaccine elicited focused immune responses to the functionally critical part of the virus sequences surrounding the PCSs. PCS-specific CD8 ${ }^{+} \mathrm{Tcm}$ cells with higher killing potential for virus-infected cells were among the $\mathrm{T}$ cell responses that correlated with vaccine efficacy. The mucosal inflammation induced by the PCS vaccine is low. The amount and activation of viral target $\mathrm{T}$ cells in the blood was significantly lower in the PCS vaccine group than that in the control group. The PCS-vaccine-immunized monkeys had significantly lower CCR5 expression in Th17 cells, lower frequencies of $\mathrm{CCR}^{+} \mathrm{IL}-17 \mathrm{~A}^{+} \mathrm{CD} 8^{+} \mathrm{T}$ naive cells, and lower expression of activation markers CD69 and CD38. These are relevant to HIV infection because Th17 cells are preferential targets for productive infection $(55,56)$ and IL-17A ${ }^{+} \mathrm{CD} 8^{+} \mathrm{T}$ cells also are thought to play a role in immune pathology that contributes to the maintenance of target cell populations for HIV infection (57). Thus, the PCS vaccine limited the availability of viral target cells. Furthermore, the PCS-vaccinated monkeys had higher frequencies of PCS-specific CD $4^{+}$ Treg EMRA and CD $4^{+} \mathrm{IL}-10^{+}$Treg naive cells than controls; thus, they may be better able to regulate antiviral immune responses. Six predictors identified using the LASSO model that predicted vaccine efficacy are all PCS-specific T cell responses including 4 PCS-specific Treg cell populations and 2 PCS-specific CD8 ${ }^{+} \mathrm{Tcm} /$ Tem cell populations. This suggests that regulation of anti-SIV $\mathrm{CD}^{+} \mathrm{T}$ cell responses is important.
These cellular responses that we observed in the blood may not reflect the ones in the mucosal tissue. Evaluation of cellular responses in the mucosal tissue for correlation with the one observed in the blood would be an important future study. From analysis of CVL mucosal cytokines during immunization we did observe a temporal increase in MCP-1 (CCL2) in the PCS vaccine group after each immunization (Figure 2A). MCP-1 is secreted by many cell types, including monocytes, macrophages, and epithelial cells (88). In addition to its role in driving the chemotaxis of myeloid and lymphoid cells (88), the cells secreting MCP-1, monocytes and macrophages, were also involved in establishing innate memory of immune tolerance (89). The PCS-vaccination-induced Treg cells, which apparently play an important role in the immune microenvironment, warrant further investigation. It is possible that innate responses contributed by MCP-1 (CCL2) and monocytes/macrophages may work together with PCS-associated $\mathrm{T}$ cell responses leading to protection, since another study has shown that monocytes and higher levels of plasma CCL2 were associated with decreased risk of SIVmac251 acquisition (90).

The PCS vaccine generated a focused and modest magnitude of protective immune responses. These antiviral immune responses in combination with low inflammation and reduced $\mathrm{CD}^{+}$ $\mathrm{CCR}^{+}$viral target cells appear to be sufficient to prevent pathogenic SIVmac251 acquisition. Because most sexual HIV transmission was initiated by a single founder virus $(91,92)$, a focused, modest-magnitude, and well-regulated antiviral immune response might be enough to prevent viral establishment and propagation, as demonstrated in this study.

In conclusion, we demonstrate that an HIV vaccine candidate that focuses immune response on sequences surrounding the 12 PCSs can protect female macaques from pathogenic SIVmac251 intravaginal acquisition. For the first time to our knowledge, a candidate HIV vaccine without full-length Gag and Env immunogens has demonstrated significant protection. Our study also showed that PCS-specific CD8 ${ }^{+} \mathrm{Tcm}$ and Tem cells, and PCS-specific $\mathrm{CD}^{+}$and $\mathrm{CD} 8^{+}$Treg cells, correlated with vaccine efficacy. Thus, these data suggest that an effective prophylactic HIV vaccine needs to not only generate effective antiviral immune responses to kill infected cells, but also regulate the immune responses and control immune activation and inflammation.

Although this study shows that the PCS vaccine is effective in preventing infection of a highly stringent NHP/SIVmac251 intravaginal challenge model, human clinical trials will constitute the ultimate test. Such trials will be facilitated by the detailed information of $\mathrm{T}$ cell epitopes surrounding the 12 HIV PCSs of major HLA class I alleles in the world populations (12), together with the immune correlates of protection identified in this study.

\section{Methods}

Additional details are provided in Supplemental Methods.

Study design. Vaccine efficacy against acquisition of infection was evaluated in female MCMs receiving repeated low-dose intravaginal challenges by SIVmac251, which mimics natural HIV infection through the female genital tract. Sample sizes were determined using the parameters described in previous studies (93). An infection rate of 
0.4 among control macaques and an interval of 2 weeks between each challenge of the mucosal repeated low-dose regimen were estimated from our pilot study. Statistical power was then calculated based on assuming an infection rate of $40 \%$ per exposure and a susceptibility to infection of $85 \%$ in control animals at the endpoint of the sixth viral challenge, when the majority of control macaques become infected. To achieve $80 \%$ statistical power with a 2 -sided type I error rate less than 0.05 , a total of 16 female MCMs were required and assigned to 2 groups (8/group): the PCS and sham control vaccine groups.

Experimental animals. All animal work was carried out at the Wisconsin National Primate Research Center. We conducted vaccine evaluation using the MCM/SIVmac251 infection model. MCMs are abundant in supply, and have simple MHC genotypes (with only 7 MHC haplotypes; refs. 69, 70, 94-98). Their infection by SIVmac251 leads to peak and set-point VLs and a disease progression pattern that closely mimic human HIV infection $(70,99,100)$. This infection model has proven stringent for testing prophylactic vaccines; none of the vaccines previously tested in this model has demonstrated significant efficacy against acquisition of SIVmac251 (or SIVmac239) infection (24, 70, 73-77, 79-81, 101-111). Additional animal information, concerning grouping, ID, gender, age, weight, and MHC haplotypes, is summarized in Supplemental Tables 1 and 2.

Immunization scheme. The PCS vaccine contained twelve 20-mer peptides, derived from the 12 PCSs of SIVmac239 (10 amino acids flanking each side of the cleavage site) $(13,112)$. These peptide immunogens were delivered as recombinant vesicular stomatitis viruses (rVSVpcs) or biodegradable nanoparticles (NANOpcs) (13). The rVSVpcs consisted of 12 different rVSV viruses, each delivering 1 PCS peptide (PCS1, PCS2, ..., or PCS12) and the NANOpcs was formed by a pool of 12 formulations, each made of chitosan/dextran sulfate nanoparticles containing a unique PCS peptide (13). The rVSVpcs and NANOpcs in combination are referred to as the PCS vaccine. The sham control vaccine was rVSV vector (rVSVvt) virus (without SIV immunogen insert) and sterile water (NANO vehicle) (13). In choosing the control for NANO, we considered the possibility that certain types of nanoparticles may activate the immune system by their own. However, this is not a common observation (113). In particular, our experience with nanosystems made of GMP-grade chitosan and dextran sulphate indicates that these nanoparticles do not elicit a significant immune activation in the absence of antigens (114). Thus, we could assume that the chitosan/dextran sulphate nanoparticles used in the study are not expected to elicit an immune response and particularly any protective response. We therefore used sterile water as a simple format of control for NANO. The vaccination scheme was described previously (13), consisting of a prime (with rVSV at week 0) and 4 boosts (first boost: rVSV + NANO at week 6, second boost: NANO at week 16, third boost: rVSV + NANO at week 51 , and fourth boost: rVSV at week 72). rVSVs were administered intramuscularly at a dose of 2 $\times 10^{7} \mathrm{pfu} / \mathrm{animal}$ (i.e., $1.67 \times 10^{6} \mathrm{pfu} / \mathrm{rVSVpcs}$ type/animal $\times 12 \mathrm{PCS}$ types $=2 \times 10^{7} \mathrm{pfu} / \mathrm{animal}$ for the PCS vaccine group, or $2 \times 10^{7} \mathrm{pfu}$ of rVSVvt/animal for the control group), except that, in the fourth boost, $1 \times 10^{8} \mathrm{pfu}$ of each rVSVpcs or rVSVvt was used. NANOpcs was administered intranasally at a dose of $50 \mu \mathrm{g}$ peptide/PCS type/animal $\times 12$ PCS types $=600 \mu \mathrm{g} / \mathrm{animal}$.

Repeated low-dose intravaginal SIVmac251 challenges. SIVmac251 viral stock ("Desrosiers" 2010 day 8 viral stock generated using rhesus PBMCs) was supplied by the NIH Vaccine Research Program,
Preclinical Research and Development Branch, Bethesda, Maryland, USA (Jon Warren and Nancy Miller). Challenges were carried out every 2 weeks starting 24 weeks after the last vaccination boost. The vast majority of SIV challenges in previous studies were performed weekly $(23,26,115)$, while viral acquisition status was monitored by quantification of plasma VL. However, establishment of systemic infection can take up to 10-14 days (54). Potentially, some slowly establishing infections may not be detectable within 1 week after challenge by the routine method of plasma VL measurement (86). Therefore, using the weekly challenge protocol, an infection identified during a later challenge round may actually have been acquired in an earlier round, leading to an overestimation of vaccine efficacy. In this regard, we carried out challenges every 2 weeks, and plasma VL was quantified on days 6,10 , and 14 of each challenge round (any animal found infected was not challenged further). Indeed, we found that in some cases an infection could remain below the detectable level until as late as 14 days following a challenge (Supplemental Table 3). In addition, we took into consideration that in females, susceptibility to vaginal HIV infection could be affected by phases of the menstrual cycle. It was reported that the susceptibility is higher in the luteal phase than in non-luteal phases (116-120). Our 2-week challenge cycle was designed to maximize the chance for even distribution of challenges in the luteal versus non-luteal phases, since the luteal phase constitutes approximately half of a 4-week menstrual cycle. It was confirmed that in both the control and PCS vaccine groups challenges fell in the luteal and non-luteal phases nearly equally, without any significant difference between the 2 groups (Supplemental Figures 1 and 2).

Intravaginal challenges were performed by atraumatically delivering $250 \times 50 \%$ tissue culture infectious doses $\left(\mathrm{TCID}_{50}\right)$ of SIVmac251 in $1 \mathrm{~mL}$ of saline or tissue culture medium to the vagina while the animal was anesthetized as described below. The virus was delivered using a TB syringe with the needle removed (or using a TB syringe with a rounded end gavage tube). The syringe was gently inserted into the vagina approximately $4 \mathrm{~cm}$, then withdrawn slightly and the dose was injected slowly over 1 minute, and then the animal's pelvic region kept elevated up to 30 minutes before returning the animal to its cage. When withdrawn, the syringe was examined to ensure that there was no trauma to the vagina inflicted by the syringe (in which case blood would be visible).

Flow cytometry. PBMCs with minimal manipulation (ex vivo) or with stimulation by the total PCS peptide pool (PCS1-12, Supplemental Table 11) were transferred to $12 \times 75 \mathrm{~mm}$ polystyrene tubes (BD Falcon) and washed with FACS wash (PBS supplemented with $2 \%$ FBS). Three sets of fluorochrome-labeled antibody cocktails (Thermo Fisher Scientific and BD Biosciences, Supplemental Table 13) were prepared, added to the washed PBMCs, and incubated at room temperature for 30 minutes in the dark. Following the surface staining, $500 \mu \mathrm{L}$ FACS wash was added to each tube to wash the cells followed by centrifugation at $1500 \mathrm{rpm}$ for 5 minutes with low brakes. Next, the cells stained with extracellular antibodies for panels 1 and 3 were permeabilized using $150 \mu \mathrm{L}$ Cytoperm/Cytofix (BD Biosciences) for 10-15 minutes, while those for panel 2 intracellular cytokine staining (ICS) were fixed using $2 \mathrm{~mL}$ of $1 \times$ FOXP3 buffer (BD Pharmingen) for 10-15 minutes. The cells (panels 1-3) were then washed using FACS wash, and incubated with ICS panel 1 and 3 antibodies for 30 minutes. Alternatively, the cells (panel 2) were further permeabilized using $1 \times$ Human FOXP3 
Buffer C (BD Pharmingen) for 30 minutes, washed using FACS wash, and finally incubated with a cocktail of ICS antibodies. Following the ICS antibody incubation, the cells (panels 1-3) were washed using FACS wash, and $300 \mu \mathrm{L} 1 \%$ formaldehyde with $1 \times$ PBS was added to each tube. Flow cytometry analysis was done on a multicolor BD LSRII cytometer with data acquisition using BD FACSDiva software. Data analysis was carried out using FlowJo (courtesy of African HIV/AIDS program/TreeStar).

Data and materials availability. The authors declare that the data supporting the findings of this study are available within the paper and its supplementary information files. The data that support the findings of this study are available from the corresponding author upon reasonable request. The materials can be made available upon request through an MTA.

Statistics. Time to infection in each group, measured by the number of challenges required to acquire infection and censored following challenge 6 on day 84, was summarized using Kaplan-Meier survival curves and compared using the log-rank test; vaccine efficacy (\%) was evaluated as $(1$ - hazard ratio $) \times 100$ in a proportional hazard regression model. Spearman's rank correlations were used to assess the associations between each immune factor and the number of challenges to infection. Immune responses were compared between the vaccine and control groups using the Mann-Whitney $U$ test. For each of the above tests, $P$ less than 0.05 was considered significant, without adjustment for multiple inferences.

LASSO analysis for a predictive model of vaccine efficacy. Our Spearman's rank analysis considered each immunologic measure individually. To identify potential combinations of immunological predictors of resistance or susceptibility, we also performed a multiple regression analysis. We used a linear model for the number of challenges survived versus the available biological measurements due to the small numbers of monkeys in each group. The linear model was fitted using the LASSO, a variant of least-squares regression with an L1 regularization term, implemented in the Python scikit-learn library v0.20.3 (121). This regularization forces most of the coefficients in the final model to be zero and selects only the most important features, to a maximum of 7 features for a group of 8 animals, before estimating the final model. The regularization parameter was selected using a leave-one-out cross-validation strategy to achieve the lowest squared prediction error averaged across the fitted models. Each feature was scaled to range from 0 to 1 to facilitate the interpretation of the regression coefficients.

Study approval. All animal experiments were approved by the University of Wisconsin (Madison, Wisconsin, USA) IACUC protocol (G005765) in accordance with the US Animal Welfare Act and following the recommendations of the National Research Council Guide for the Care and Use of Laboratory Animals, 8th edition (National Academies Press, 2011), and the Weatherall report, "The Use of Nonhuman Primates in Research." The Wisconsin National Primate Research Center (Madison, Wisconsin, USA) is fully accredited by AAALAC under the University of Wisconsin, Division of Vice-Chancellor for Research and Graduate Education.

\section{Author contributions}

ML designed and coordinated the study with NSD, MJA, QL, JBW, DS, JCC, HL, NT, and RWO. HL, BL, RWO, ML, RFB, and $\mathrm{ABL}$ interpreted the data. HL drafted the manuscript. BL, RFB,
$\mathrm{ABL}$, and $\mathrm{XQL}$ analyzed the vaccine efficacy data, performed statistical analysis, LASSO analysis, the correlates of protection/ risk analyses, prepared the figures, and helped to write the manuscript. RWO performed the flow cytometry analysis for PBMCs and helped to write the manuscript. HL prepared the rVSVs for vaccinations, performed the studies on antibodies together with LRL and YH, analyzed the antibody data, prepared some figures and tables, and drafted the manuscript together with ML. NT performed the analysis of CVL cytokines and data analysis with RWO and MAK. MSS conducted plasma antibody neutralization assays. NSD coordinated the animal studies with DS (who performed sampling, immunization, and challenge experiments together with animal care technicians). MJA, JCC, JFCP, and TGD provided the nanoformulated PCS vaccine for immunization and boost. QL and YW performed data acquisition and analysis. FAP, SYL, QL, JBW, and NSD helped to write the manuscript. ML, FAP, NSD, MJA, and JBW secured funding for this study. LL helped with statistical analysis.

\section{Acknowledgments}

We would like to dedicate this manuscript to Francis A. Plummer, a coauthor, a mentor, and a world-renowned scientist, academic, and HIV/AIDS researcher, who passed away on February 4, 2020, in Nairobi, Kenya, while attending the celebration of the 40th anniversary of the Manitoba/Kenya research collaboration. His research on the HIV-resistant Kenyan female sex workers contributed to the development of the PCS vaccine. We thank staff at Wisconsin National Primate Research Center Scientific Protocol Implementation Unit and Immunology Services Unit, especially Eva Rakasz, for important technical support. We thank Stuart Shapiro, NIH Vaccine Research Program, and Matthew Gilmour, National Microbiology Laboratory of Canada, for their support and discussion. We thank Jon Warren and Nancy Miller for providing SIVmac251 "Desrosiers" 2010 day 8 viral stock and NIH AIDS Reagent Program for providing SIV and HIV antibodies, antigens, and other important reagents. We thank Wallace Trenholm and Mark Alexiuk of Sightline Innovation for supporting LASSO analysis. We express our appreciation to Greg Hammond, Allan Ronald, and Jo Kennelly for their support for this vaccine study. This work was supported by an NIH grant (R01AI111805), a CIHR/ CHVI bridge grant, and funding from the National Microbiology Laboratory, Public Health Agency of Canada. Research reported in this publication was supported in part by the Office of the Director, NIH, under award number P51OD011106 to the Wisconsin National Primate Research Center, University of WisconsinMadison. This research was conducted (or conducted in part) at a facility constructed with support from Research Facilities Improvement Program grant numbers RR15459-01 and RR020141-01. The content is solely the responsibility of the authors and does not necessarily represent the official views of the NIH.

Address correspondence to: Ma Luo, JC Wilt Infectious Diseases Research Center, National Microbiology Laboratory, 745 Logan Avenue, Winnipeg, Manitoba R3E 3L5, Canada; or Department of Medical Microbiology and Infectious Diseases, University of Manitoba, Winnipeg, Manitoba R3E 0J9, Canada. Email: ma.luo@ canada.ca or Ma.Luo@umanitoba.ca. 
1. Li Q, et al. Glycerol monolaurate prevents mucosal SIV transmission. Nature. 2009;458(7241):1034-1038.

2. Li Q, et al. Visualizing antigen-specific and infected cells in situ predicts outcomes in early viral infection. Science. 2009;323(5922):1726-1729.

3. Passmore JA, Jaspan HB, Masson L. Genital inflammation, immune activation and risk of sexual HIV acquisition. Curr Opin HIV AIDS. 2016;11(2):156-162.

4. Lewis GK, DeVico AL, Gallo RC. Antibody persistence and T-cell balance: two key factors confronting HIV vaccine development. Proc Natl Acad Sci U S A. 2014;111(44):15614-15621.

5. Boettler T, Cunha-Neto E, Kalil J, von Herrath M. Can an immune-regulatory vaccine prevent HIV infection? Expert Rev Anti Infect Ther. 2012;10(3):299-305

6. Tomaras GD, Plotkin SA. Complex immune correlates of protection in HIV-1 vaccine efficacy trials. Immunol Rev. 2017;275(1):245-261.

7. Promadej-Lanier N, et al. Systemic and mucosal immunological responses during repeated mucosal SHIV(162P3) challenges prior to and following infection in pigtailed macaques. Virology. 2008;375(2):492-503.

8. Li H, Omange RW, Plummer FA, Luo M. A novel HIV vaccine targeting the protease cleavage sites. AIDS Res Ther. 2017;14(1):51.

9. Luo M, et al. For protection from HIV-1 infection, more might not be better: a systematic analysis of HIV Gag epitopes of two alleles associated with different outcomes of HIV-1 infection. J Virol. 2012;86(2):1166-1180.

10. Alimonti JB, et al. Characterization of CD8 T-cell responses in HIV-1-exposed seronegative commercial sex workers from Nairobi, Kenya. Immunol Cell Biol. 2006;84(5):482-485.

11. Alimonti JB, et al. CD $4^{+} \mathrm{T}$ cell responses in HIV-exposed seronegative women are qualitatively distinct from those in HIV-infected women. Jinfect Dis. 2005;191(1):20-24.

12. Luo M, et al. Immunogenicity of sequences around HIV-1 protease cleavage sites: potential targets and population coverage analysis for a HIV vaccine targeting protease cleavage sites. Vaccine. 2013;31(29): 3000-3008.

13. Li H, et al. Mucosal antibody responses to vaccines targeting SIV protease cleavage sites or full-length Gag and Env proteins in Mauritian cynomolgus macaques. PLoS One. 2018;13(8):e0202997.

14. de Oliveira T, et al. Variability at human immunodeficiency virus type 1 subtype $\mathrm{C}$ protease cleavage sites: an indication of viral fitness? J Virol. 2003;77(17):9422-9430.

15. Muller B, et al. HIV-1 Gag processing intermediates trans-dominantly interfere with HIV-1 infectivity. J Biol Chem. 2009;284(43):29692-29703.

16. Pettit SC, et al. The $\mathrm{p} 2$ domain of human immunodeficiency virus type $1 \mathrm{Gag}$ regulates sequential proteolytic processing and is required to produce fully infectious virions. J Virol. 1994;68(12):8017-8027.

17. Pettit SC, Everitt LE, Choudhury S, Dunn BM, Kaplan AH. Initial cleavage of the human immunodeficiency virus type $1 \mathrm{GagPol}$ precursor by its activated protease occurs by an intramolecular mechanism. J Virol. 2004;78(16):8477-8485.

18. Pettit SC, Clemente JC, Jeung JA, Dunn BM, Kaplan AH. Ordered processing of the human immunodeficiency virus type $1 \mathrm{GagPol}$ precursor is influenced by the context of the embedded viral protease. J Virol. 2005;79(16):10601-10607.

19. Pettit SC, Lindquist JN, Kaplan AH, Swanstrom R. Processing sites in the human immunodeficiency virus type 1 (HIV-1) Gag-Pro-Pol precursor are cleaved by the viral protease at different rates. Retrovirology. 2005;2:66.

20. Pettit SC, Henderson GJ, Schiffer CA, Swanstrom R. Replacement of the $\mathrm{P} 1$ amino acid of human immunodeficiency virus type $1 \mathrm{Gag}$ processing sites can inhibit or enhance the rate of cleavage by the viral protease. J Virol. 2002;76(20):10226-10233.

21. Wiegers K, Rutter G, Kottler H, Tessmer U, Hohenberg H, Krausslich HG. Sequential steps in human immunodeficiency virus particle maturation revealed by alterations of individual Gag polyprotein cleavage sites. J Virol. 1998;72(4):2846-2854.

22. Kaplan AH, et al. Partial inhibition of the human immunodeficiency virus type 1 protease results in aberrant virus assembly and the formation of noninfectious particles. J Virol. 1993;67(7):4050-4055

23. Barouch $\mathrm{DH}$, et al. Vaccine protection against acquisition of neutralization-resistant SIV challenges in rhesus monkeys. Nature. 2012;482(7383):89-93.

24. Li H, et al. Mauritian cynomolgus macaques with M3M4 MHC genotype control SIVmac251 infection. JMed Primatol. 2017;46(4):137-143.

25. Pavot V, et al. Recent progress in HIV vaccines inducing mucosal immune responses. AIDS, 2014;28(12):1701-1718.

26. Barouch DH, et al. Protective efficacy of adenovirus/protein vaccines against SIV challenges in rhesus monkeys. Science. 2015;349(6245):320-324.

27. HIPC-CHI Signatures Project Team, HIPC-I Consortium. Multicohort analysis reveals baseline transcriptional predictors of influenza vaccination responses. Sci Immunol. 2017;2(14):eaal4656.

28. Martins MA, et al. Vaccine protection against SIVmac239 acquisition. Proc Natl Acad Sci U S A. 2019;116(5):1739-1744.

29. Chamcha V, et al. Strong TH1-biased CD4 $\mathrm{T}$ cell responses are associated with diminished SIV vaccine efficacy. Sci Transl Med. 2019;11(519):eaav1800.

30. Peng B, et al. Rhesus macaque resistance to mucosal simian immunodeficiency virus infection is associated with a postentry block in viral replication. J Virol. 2002;76(12):6016-6026.

31. Letvin NL, et al. No evidence for consistent virus-specific immunity in simian immunodeficiency virus-exposed, uninfected rhesus monkeys. J Virol. 2007;81(22):12368-12374.

32. Promadej-Lanier N, et al. Resistance to Simian HIV infection is associated with high plasma interleukin-8, RANTES and Eotaxin in a macaque model of repeated virus challenges. J Acquir Immune Defic Syndr. 2010;53(5):574-581.

33. Veazey RS, Shattock RJ, Klasse PJ, Moore JP. Animal models for microbicide studies. Curr HIV
Res. 2012;10(1):79-87.

34. Byrareddy SN, et al. Targeting alpha4beta7 integrin reduces mucosal transmission of simian immunodeficiency virus and protects gutassociated lymphoid tissue from infection. Nat Med. 2014;20(12):1397-400.

35 . Bradley T, et al. Pentavalent HIV-1 vaccine protects against simian-human immunodeficiency virus challenge. Nat Commun. 2017;8:15711.

36. Martins MA, et al. Vaccine-induced immune responses against both Gag and Env improve control of simian immunodeficiency virus replication in rectally challenged rhesus macaques. PLoS Pathog. 2017;13(7):e1006529.

37. Masson L, et al. Genital inflammation and the risk of HIV acquisition in women. Clin Infect Dis. 2015;61(2):260-269.

38. Arnold KB, et al. Increased levels of inflammatory cytokines in the female reproductive tract are associated with altered expression of proteases, mucosal barrier proteins, and an influx of HIV-susceptible target cells. Mucosal Immunol. 2016;9(1):194-205.

39. McKinnon LR, et al. Genital inflammation undermines the effectiveness of tenofovir gel in preventing HIV acquisition in women. Nat Med. 2018;24(4):491-496.

40. Huse M, Lillemeier BF, Kuhns MS, Chen DS, Davis MM. T cells use two directionally distinct pathways for cytokine secretion. Nat Immunol. 2006;7(3):247-255.

41. Kenway-Lynch CS, Das A, Lackner AA, Pahar B. Cytokine/chemokine responses in activated $\mathrm{CD}^{+}$and $\mathrm{CD}^{+} \mathrm{T}$ cells isolated from peripheral blood, bone marrow, and axillary lymph nodes during acute simian immunodeficiency virus infection. J Virol. 2014;88(16):9442-9457.

42. Teigler JE, Iampietro MJ, Barouch DH. Vaccination with adenovirus serotypes 35,26 , and 48 elicits higher levels of innate cytokine responses than adenovirus serotype 5 in rhesus monkeys. J Virol. 2012;86(18):9590-9598.

43. Makedonas G, Betts MR. Polyfunctional analysis of human $t$ cell responses: importance in vaccine immunogenicity and natural infection. Springer Semin Immunopathol. 2006;28(3):209-219.

44. Cocchi F, DeVico AL, Garzino-Demo A, Arya SK, Gallo RC, Lusso P. Identification of RANTES, MIP-1 alpha, and MIP-1 beta as the major HIV-suppressive factors produced by $\mathrm{CD} 8^{+} \mathrm{T}$ cells. Science. 1995;270(5243):1811-1815.

45. Kishimoto T. The biology of interleukin-6. Blood. 1989;74(1):1-10.

46. Tilg H, Trehu E, Atkins MB, Dinarello CA, Mier JW. Interleukin-6 (IL-6) as an anti-inflammatory cytokine: induction of circulating IL-1 receptor antagonist and soluble tumor necrosis factor receptor p55. Blood. 1994;83(1):113-118.

47. Xing Z, et al. IL-6 is an antiinflammatory cytokine required for controlling local or systemic acute inflammatory responses. J Clin Invest. 1998;101(2):311-320.

48. Himmel ME, Crome SQ, Ivison S, Piccirillo C, Steiner TS, Levings MK. Human $\mathrm{CD}^{+} \mathrm{FOXP3}^{+}$ regulatory $\mathrm{T}$ cells produce CXCL8 and recruit neutrophils. Eur J Immunol. 2011;41(2):306-312.

49. Sallusto F, Lenig D, Forster R, Lipp M, Lanzavecchia A. Two subsets of memory T lymphocytes 
with distinct homing potentials and effector functions. Nature. 1999;401(6754):708-712.

50. Sallusto F, et al. Switch in chemokine receptor expression upon TCR stimulation reveals novel homing potential for recently activated $\mathrm{T}$ cells. Eur JImmunol. 1999;29(6):2037-2045.

51. Rosenblum MD, Way SS, Abbas AK. Regulatory T cell memory. Nat Rev Immunol.2016;16(2):90-101.

52. Sathaliyawala T, et al. Distribution and compartmentalization of human circulating and tissue-resident memory T cell subsets. Immunity. 2013;38(1):187-197.

53. Masopust D, Picker LJ. Hidden memories: frontline memory $\mathrm{T}$ cells and early pathogen interception. J Immunol. 2012;188(12):5811-5817.

54. Poudrier J, Thibodeau V, Roger M. Natural immunity to HIV: a delicate balance between strength and control. Clin Dev Immunol. 2012;2012:875821.

55. Christensen-Quick A, Lafferty M, Sun L, Marchionni L, DeVico A, Garzino-Demo A. Human Th17 cells lack HIV-inhibitory RNases and are highly permissive to productive HIV infection. J Virol. 2016;90(17):7833-7847.

56. Rodriguez-Garcia M, Barr FD, Crist SG, Fahey JV, Wira CR. Phenotype and susceptibility to HIV infection of $\mathrm{CD}^{+}{ }^{+} \mathrm{Th} 17$ cells in the human female reproductive tract. Mucosal Immunol. 2014;7(6):1375-1385.

57. Srenathan U, Steel K, Taams LS. IL- $17^{+} \mathrm{CD} 8^{+}$ $T$ cells: differentiation, phenotype and role in inflammatory disease. Immunol Lett. 2016;178:20-26.

58. Lynch RM, et al. HIV-1 fitness cost associated with escape from the VRC01 class of CD4 binding site neutralizing antibodies. J Virol. 2015;89(8):4201-4213.

59. Sheng Z, et al. Effects of Darwinian selection and mutability on rate of broadly neutralizing antibody evolution during HIV-1 infection. PLoS Comput Biol. 2016;12(5):e1004940.

60. Sunshine JE, et al. Fitness-balanced escape determines resolution of dynamic founder virus escape processes in HIV-1 infection. J Virol. 2015;89(20):10303-10318.

61. Shapiro SZ. Lessons for general vaccinology research from attempts to develop an HIV vaccine. Vaccine. 2019;37(26):3400-3408.

62. Pantophlet R, Burton DR. GP120: target for neutralizing HIV-1 antibodies. Annu Rev Immunol. 2006;24:739-769.

63. Rolland M, Nickle DC, Mullins JI. HIV-1 group $\mathrm{M}$ conserved elements vaccine. PLoS Pathog. 2007;3(11):e157.

64. Fauci AS, Marovich MA, Dieffenbach CW, Hunter E, Buchbinder SP. Immunology. Immune activation with HIV vaccines. Science. 2014;344(6179):49-51.

65. Ackerman ME, et al. Polyfunctional HIVspecific antibody responses are associated with spontaneous HIV control. PLoS Pathog. 2016;12(1):e1005315.

66. Nitayaphan S, et al. Safety and immunogenicity of an HIV subtype $B$ and $E$ prime-boost vaccine combination in HIV-negative Thai adults. Infect Dis. 2004;190(4):702-706.

67. McElrath MJ, et al. HIV-1 vaccine-induced immunity in the test-of-concept Step Study: a case-cohort analysis. Lancet. 2008;372(9653):1894-1905.

68. Vaccari M, et al. Adjuvant-dependent innate and adaptive immune signatures of risk of SIVmac251 acquisition. Nat Med.2016;22(7):762-770.

69. Sui Y, Gordon S, Franchini G, Berzofsky JA. Nonhuman primate models for HIV/AIDS vaccine development. Curr Protoc Immunol. 2013;102:Unit 12.14.

70. Antony JM, MacDonald KS. A critical analysis of the cynomolgus macaque, Macaca fascicularis, as a model to test HIV-1/SIV vaccine efficacy. Vaccine. 2015;33(27):3073-3083.

71. Del Prete GQ, Lifson JD, Keele BF. Nonhuman primate models for the evaluation of HIV-1 preventive vaccine strategies: model parameter considerations and consequences. Curr Opin HIV AIDS. 2016;11(6):546-554.

72. O'Connor SL, et al. MHC heterozygote advantage in simian immunodeficiency virus-infected Mauritian cynomolgus macaques. Sci Transl Med. 2010;2(22):22ra18.

73. Hu SL, et al. Protection of macaques against SIV infection by subunit vaccines of SIV envelope glycoprotein gp160. Science. 1992;255(5043):456-459.

74. Mederle I, et al. Mucosal administration of three recombinant Mycobacterium bovis BCG-SIVmac251 strains to cynomolgus macaques induces rectal IgAs and boosts systemic cellular immune responses that are primed by intradermal vaccination. Vaccine. 2003;21(27-30):4153-4166.

75. Beignon AS, et al. Lentiviral vector-based prime/ boost vaccination against AIDS: pilot study shows protection against Simian immunodeficiency virus SIVmac251 challenge in macaques. JVirol. 2009;83(21):10963-10974.

76. Willer DO, et al. Multi-low-dose mucosal simian immunodeficiency virus SIVmac239 challenge of cynomolgus macaques immunized with "hyperattenuated" SIV constructs. J Virol. 2010;84(5):2304-2317.

77. Marsh AK, Willer DO, Skokovets O, Iwajomo $\mathrm{OH}$, Chan JK, MacDonald KS. Evaluation of cynomolgus macaque (Macaca fascicularis) endogenous retrovirus expression following simian immunodeficiency virus infection. PLoS One. 2012;7(6):e40158

78. Baroncelli S, Negri DR, Michelini Z, Cara A. Macaca mulatta, fascicularis and nemestrina in AIDS vaccine development. Expert Rev Vaccines. 2008;7(9):1419-1434.

79. Michelini Z, et al. T-cell-mediated protective efficacy of a systemic vaccine approach in cynomolgus monkeys after SIV mucosal challenge. JMed Primatol. 2004;33(5-6):251-261.

80. Negri DR, et al. Protective efficacy of a multicomponent vector vaccine in cynomolgus monkeys after intrarectal simian immunodeficiency virus challenge. J Gen Virol. 2004;85(pt 5):1191-1201.

81. Negri DR, et al. Effect of vaccination with recombinant modified vaccinia virus Ankara expressing structural and regulatory genes of SIV(macj5) on the kinetics of SIV replication in cynomolgus monkeys. J Med Primatol. 2001;30(4):197-206.

82. Hazan $\mathrm{H}$, et al. BindsNET: a machine learningoriented spiking neural networks library in Python. Front Neuroinform. 2018;12:89.

83. ten Haaft P, et al. Comparison of early plasma RNA loads in different macaque species and the impact of different routes of exposure on SIV/SHIV infection. JMed Primatol. 2001;30(4):207-214.

84. Gupta P, et al. High viral load in semen of human immunodeficiency virus type 1 -infected men at all stages of disease and its reduction by therapy with protease and nonnucleoside reverse transcriptase inhibitors. J Virol. 1997;71(8):6271-6275.

85. Del Prete GQ, et al. Comparative characterization of transfection- and infection-derived simian immunodeficiency virus challenge stocks for in vivo nonhuman primate studies. J Virol. 2013;87(8):4584-4595.

86. Liang B, Li H, Li L, Omange RW, Hai Y, Luo M. Current advances in HIV vaccine preclinical studies using Macaque models. Vaccine. 2019;37(26):3388-3399.

87. Hansen SG, et al. Profound early control of highly pathogenic SIV by an effector memory T-cell vaccine. Nature. 2011;473(7348):523-527.

88. Gschwandtner M, Derler R, Midwood KS. More than just attractive: how CCL2 influences myeloid cell behavior beyond chemotaxis. Front Immunol. 2019;10:2759.

89. Netea MG, et al. Trained immunity: a program of innate immune memory in health and disease. Science. 2016;352(6284):aaf1098.

90. Vaccari M, et al. HIV vaccine candidate activation of hypoxia and the inflammasome in CD14(+) monocytes is associated with a decreased risk of SIVmac251 acquisition. Nat Med. 2018;24(6):847-856.

91. Baum LL. Role of humoral immunity in host defense against HIV. Curr HIV/AIDS Rep. 2010;7(1):11-18.

92. Visciano ML, et al. Characterization of humoral responses to soluble trimeric HIV gp140 from a clade A Ugandan field isolate. J Transl Med. 2013;11:165.

93. Hudgens MG, Gilbert PB, Mascola JR, Wu CD, Barouch DH, Self SG. Power to detect the effects of HIV vaccination in repeated low-dose challenge experiments. J Infect Dis. 2009;200(4):609-613.

94. Nishijima T, et al. Urinary beta-2 microglobulin and alpha-1 microglobulin are useful screening markers for tenofovir-induced kidney tubulopathy in patients with HIV-1 infection: a diagnostic accuracy study. J Infect Chemother. 2013;19(5):850-857.

95. Melander A, et al. 35th Annual Meeting of the European Association for the Study of Diabetes: Brussels, Belgium, 28 September-2 October 1999. Diabetologia. 1999;42(suppl 1):A1-A330.

96. Kaufmann I, Draenert R, Gruber M, Feuerecker M, Roider J, Chouker A. A new cytokine release assay: a simple approach to monitor the immune status of HIV-infected patients. Infection. 2013;41(3):687-690

97. Hatem A, Bozdag D, Toland AE, Catalyurek UV. Benchmarking short sequence mapping tools. BMC Bioinformatics. 2013;14:184.

98. Berzi A, et al. Pseudo-mannosylated DC-SIGN ligands as potential adjuvants for HIV vaccines. Viruses. 2014;6(2):391-403.

99. Hatziioannou T, Evans DT. Animal models for HIV/AIDS research. Nat Rev Microbiol. 2012;10(12):852-867. 
100.Smith KN, et al. Effective cytotoxic T lymphocyte targeting of persistent HIV-1 during antiretroviral therapy requires priming of naive $\mathrm{CD} 8^{+} \mathrm{T}$ cells. mBio. 2016;7(3):e00473-16.

101.Stott EJ. Anti-cell antibody in macaques. Nature. 1991;353(6343):393.

102. Gallimore A, et al. Early suppression of SIV replication by $\mathrm{CD} 8^{+}$nef-specific cytotoxic $\mathrm{T}$ cells in vaccinated macaques. Nat Med. 1995;1(11):1167-1173.

103. Almond N, Kent K, Cranage M, Rud E, Clarke B, Stott EJ. Protection by attenuated simian immunodeficiency virus in macaques against challenge with virus-infected cells. Lancet. 1995;345(8961):1342-1344.

104. Mills KH, et al. Vaccine-induced CD $4^{+} \mathrm{T}$ cells against the simian immunodeficiency virus gag protein. JImmunol. 1991;147(10):3560-3567.

105. Lun WH, et al. Loss of virus-specific CD4(+) T cells with increases in viral loads in the chronic phase after vaccine-based partial control of primary simian immunodeficiency virus replication in macaques. J Gen Virol. 2004;85(pt 7):1955-1963.

106.Berry N, et al. Immunological responses and viral modulatory effects of vaccination with recombinant modified vaccinia virus Ankara (rMVA) expressing structural and regulatory transgenes of simian immunodeficiency virus (SIVmac32H/ J5M). J Med Primatol. 2007;36(2):80-94.

107. Maggiorella MT, et al. Multiprotein genetic vaccine in the SIV-Macaca animal model: a promising approach to generate sterilizing immunity to HIV infection. JMed Primatol. 2007;36(4-5):180-194.

108. Martinon F, et al. Improved protection against simian immunodeficiency virus mucosal challenge in macaques primed with a DNA vaccine and boosted with the recombinant modified vaccinia virus Ankara and recombinant Semliki Forest virus. Vaccine. 2008;26(4):532-545.

109. Hirao LA, Hokey DA, Morrow MP, Jure-Kunkel $\mathrm{MN}$, Weiner DB. Immune modulation through $4-1 B B$ enhances SIV vaccine protection in non-human primates against SIVmac251 challenge. PLoS One. 2011;6(9):e24250.

110. Mattiuzzo G, Rose NJ, Almond N, Towers GJ, Berry N. Upregulation of TRIM5alpha gene expression after live-attenuated simian immunodeficiency virus vaccination in Mauritian cynomolgus macaques, but TRIM5alpha genotype has no impact on virus acquisition or vaccination outcome. J Gen Virol. 2013;94(pt 3):606-611.

111. Berry N, et al. Early potent protection against heterologous SIVsmE660 challenge following live attenuated SIV vaccination in Mauritian cynomolgus macaques. PLoS One. 2011;6(8):e23092.

112. Li H, et al. Natural and cross-inducible anti-SIV antibodies in Mauritian cynomolgus macaques. PLoS One. 2017;12(10): 0186079.

113. Dacoba TG, Olivera A, Torres D, CrecenteCampo J, Alonso MJ. Modulating the immune system through nanotechnology. Semin Immunol. 2017;34:78-102.
114. Crecente-Campo J, et al. Bilayer polymeric nanocapsules: a formulation approach for a thermostable and adjuvanted E. coli antigen vaccine. J Control Release. 2018;286:20-32.

115. Barouch DH, et al. Protective efficacy of a global HIV-1 mosaic vaccine against heterologous SHIV challenges in rhesus monkeys. Cell. 2013;155(3):531-539.

116. Wira CR, Fahey JV. A new strategy to understand how HIV infects women: identification of a window of vulnerability during the menstrual cycle. AIDS. 2008;22(15):1909-1917.

117. Vishwanathan SA, et al. High susceptibility to repeated, low-dose, vaginal SHIV exposure late in the luteal phase of the menstrual cycle of pigtail macaques. J Acquir Immune Defic Syndr. 2011;57(4):261-264.

118. Saba E, et al. Productive HIV-1 infection of human cervical tissue ex vivo is associated with the secretory phase of the menstrual cycle. Mucosal Immunol. 2013;6(6):1081-1090.

119. Kersh EN, et al. SHIV susceptibility changes during the menstrual cycle of pigtail macaques. JMed Primatol. 2014;43(5):310-316.

120. Birse K, et al. Molecular signatures of immune activation and epithelial barrier remodeling are enhanced during the luteal phase of the menstrual cycle: implications for HIV susceptibility. J Virol. 2015;89(17):8793-8805.

121. Pedregosa F, et al. Scikit-learn: machine learning in Python. J Mach Learn Res.2011;12:2825-2830. 